ANL- 6863

Reactor Technology

(TID-4500, 33rd Ed.)

AEC Research and

Development Report

ARGONNE NATIONAI LABORATORY

9700 South Cass Avenue

Argonne, Illinois 60440

STABILITY CONSIDERATIONS FOR A PLUTONIUM LOADING IN EBR-I

by

R. R. Smith, R. O. Haroldsen, and F. D. McGinnis

Idaho Division

May 1964

Operated by The University of Chicago under

Contract W-31-109-eng-38

with the

U. S. Atomic Energy Commission 


\section{DISCLAIMER}

This report was prepared as an account of work sponsored by an agency of the United States Government. Neither the United States Government nor any agency Thereof, nor any of their employees, makes any warranty, express or implied, or assumes any legal liability or responsibility for the accuracy, completeness, or usefulness of any information, apparatus, product, or process disclosed, or represents that its use would not infringe privately owned rights. Reference herein to any specific commercial product, process, or service by trade name, trademark, manufacturer, or otherwise does not necessarily constitute or imply its endorsement, recommendation, or favoring by the United States Government or any agency thereof. The views and opinions of authors expressed herein do not necessarily state or reflect those of the United States Government or any agency thereof. 


\section{DISCLAIMER}

Portions of this document may be illegible in electronic image products. Images are produced from the best available original document. 
TABLE OF CONTENTS

$\underline{\text { Page }}$

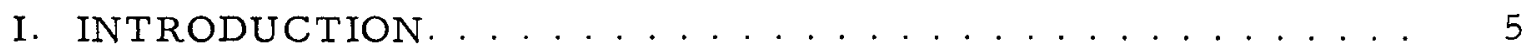

II. REVIEW OF STABILITY CONSIDERATIONS IN SMALL

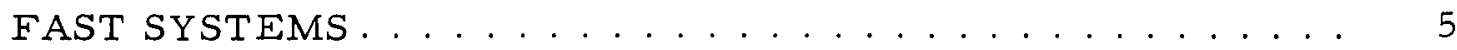

III. TRANSFER FUNCTION MEASUREMENTS . . . . . . . . . . 9

A. Description of the Mark-IV Loading. . . . . . . . . . . 9

B. Oscillator Rod and Drive System. . . . . . . . . . 10

C. Null Balance Method.................... 11

D. Zero Power Transfer Function............. 13

E. Calculated Zero Power Transfer Function .......... 15

F. Experimental Zero Power Transfer Function . . . . . . . 16

G. Transfer Function Measurements at Power......... 18

IV. RESULTS AND ANALYSIS . . . . . . . . . . . . . . . . . 24

A. Feedback Separation.................. 24

B. Feedback Model..................... 26

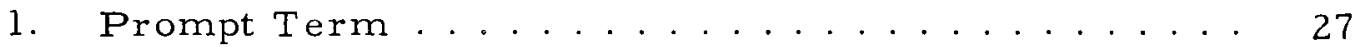

a. Axial Expansion of the Fuel.......... 27

b. NaK Expulsion................ 28

c. Radial Expansion of the Jackets ......... 28

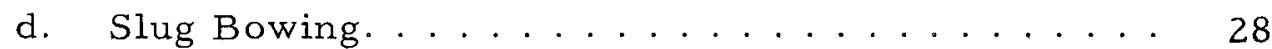

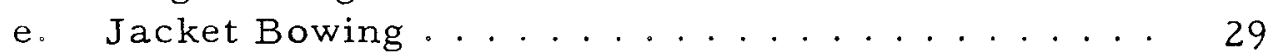

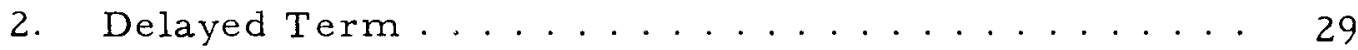

a. NaK Expulsion............... 29

b. Radial Expansion of the Jackets .......... 30

c. Jacket Bowing ............... 30

d. Structural Expansion. ............ 30

3. Mathematical Description of the Prompt Term .... 30

4. Mathematical Reduction of the Prompt Term. . . . . 32

5. Mathematical Description of the Delayed Term . . . . 32

6. The Significance of the Simplified Model. . . . . . . 33

C. Evaluation of $\mathrm{A}_{0}, \mathrm{~B}_{0}, \tau_{1}$, and $\tau_{2} \ldots \ldots 33$

D. Significance of Parametric Values............ 37

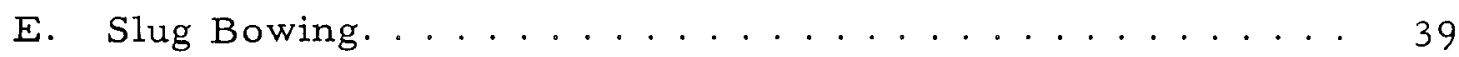

F. Additional Slug-bowing Evidence............. 41 


\section{TABLE OF CONTENTS}

Page

1. Power Coefficient Measurements ........... . 41

2. Irregularities in the Power Coefficient. . . . . . . 44

G. Effect of Inlet Temperature on Feedback . . . . . . . . . 44

H. Effect of Inlet Temperature on the Dynamic Power Coefficient .................. 47

I. Stability Considerations. . . . . . . . . . . . 48

1. Nyquist Stability Criterion. . . . . . . . . . 48

2. Extrapolation of the Transfer Function. . . . . . 49

3. The Effect of $\beta_{\text {eff }}$ on Stability............ 50

V. SUMMARY, CONCLUSIONS, AND IMPLICATIONS . . . . . . 52

VI. ACKNOW LEDGMENTS . . . . . . . . . . . . . . . . 55

VII. REFERENCES ......................... 55 


\section{LIST OF FIGURES}

No.

1. Vertical Cross Section through EBR-I, Mark IV. . . . . . . . 9 9

2. Oscillator Scheme for EBR-I ............... 11

3. Zero Power Transfer Function................ 16

4. Load Power Transfer Function for $510 \mathrm{~kW}, 265 \mathrm{gpm}$,

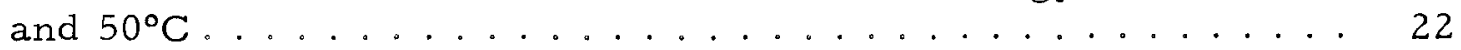

5. Load Power Transfer Function for $878 \mathrm{~kW}, 281 \mathrm{gpm}$,

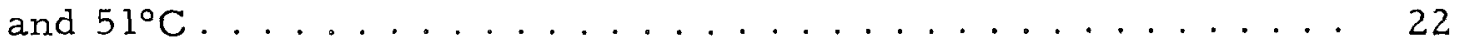

6. Load Power Transfer Function for $1193 \mathrm{~kW}, 286 \mathrm{gpm}$,

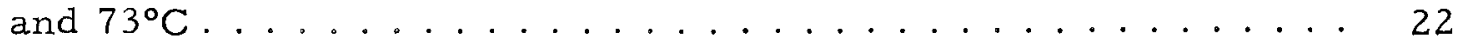

7. Load Power Transfer Function for $1120 \mathrm{~kW}, 291 \mathrm{gpm}$,

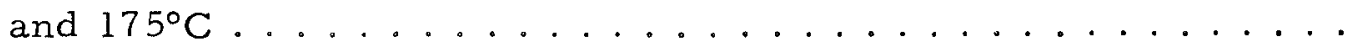

8. Load Power Transfer Function for $930 \mathrm{~kW}, 294 \mathrm{gpm}$,

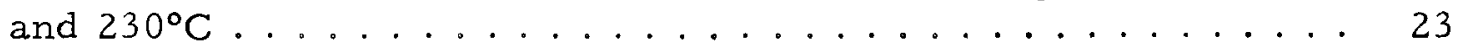

9. Comparison of Feedback .................. 25

10. Comparison of Experimental and Calculated Feedbacks for $510 \mathrm{~kW}, 265 \mathrm{gpm}$, and $50^{\circ} \mathrm{C} \ldots \ldots \ldots \ldots \ldots \ldots \ldots \ldots \ldots \ldots$

11. Comparison of Experimental and Calculated Feedbacks for $878 \mathrm{~kW}, 28 \mathrm{lgpm}$, and $51^{\circ} \mathrm{C} \ldots \ldots \ldots \ldots$

12. Comparison of Experimental and Calculated Feedbacks

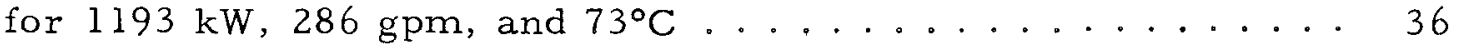

13. Comparison of Experimental and Calculated Feedbacks for $1120 \mathrm{~kW}, 291 \mathrm{gpm}$, and $175^{\circ} \mathrm{C} \ldots \ldots \ldots \ldots \ldots \ldots \ldots \ldots \ldots \ldots$

14. Comparison of Experimental and Calculated Feedbacks for $930 \mathrm{~kW}, 294 \mathrm{gpm}$, and $230^{\circ} \mathrm{C} \ldots \ldots \ldots \ldots \ldots \ldots \ldots$

15. Cross Section through Mark-IV Fuel Rod ............ 40

16. Fuel Slug Bowing ...................... 40

17. Inlet Temperature Effect. . . . . . . . . . . . 45

18. Nyquist Stability Criterion. . . . . . . . . . . . . . 49

19. Extrapolated Transfer Functions. ............... 49

20. The Effect of Third-quadrant Feedback on the Phase and Amplitude of the Transfer Function.............. 50

21. The Effect of Fourth-quadrant Feedback on the Phase and Amplitude of the Transfer Function .............. 50 


\section{LIST OF TABLES}

No.

Title

Page

I. Mark-IV Core and Blanket Composition ........... 10

II. Relative Worths of Prompt and Delayed Neutrons for Idealized Three-region Mark-IV System............ 14

III. $\beta$ eff for EBR-I, Mark IV (Radial Sphere with Lead Cup) . . . 15

IV. Effective Delayed-neutron Parameters for EBR-I, Mark IV . . 15

V. Summary of Transfer Function Data . . . . . . . . . 19

VI. Summary of Reactivity Feedback Separations ......... 25

VII. Summary of Best-fit Parametric Data .......... 34

VIII. Power Coefficient Measurements for EBR-I, Mark IV. . . . 42

IX. Average Power Coefficient Values. . . . . . . . . . . 43

X. Summary of Dynamic Power Coefficients ........... 47 


\title{
STABILITY CONSIDERATIONS FOR A PLUTONIUM LOADING IN EBR-I
}

\author{
by
}

\author{
R. R. Smith, R. O. Haroldsen, \\ and F. D. McGinnis
}

\section{INTRODUCTION}

The recent successful operation of EBR-I with a plutonium loading (Mark IV) is historically significant since EBR-I is clearly the first powerproducing system to be fueled exclusively with plutonium. Other reactors have, of course, been fueled either in whole or in part with plutonium, but in none of these was useful electric power produced.(1-3)

The exact significance of the Mark-IV loading within the framework of the fast reactor program is difficult to assess and is, in many respects, intangible. Since the physical and neutronic features of the system have little in common with those of the very large dilute plutonium-fueled systems envisioned for ultimate central station use, its successful operation cannot be used as a broad indication of future success. The operation of Mark IV has accomplished little, if anything, to lessen technical difficulties which confront the designers of more visionary plutonium-fueled systems. On the other hand, it is at least reassuring, if not necessary, to know there is nothing inherently unsafe or dangerous in the operation of a plutonium-fueled system. Such reassurance assumes added significance when it is realized that at one time the operation of EBR-I was characterized by instability problems. The eventual elimination of the source of instability and the successful operation with plutonium fuel are facts which conceivably could influence the location of future fast reactors.

Other contributions, of a more tangible nature, are illustrated by a measurement of the breeding gain and an analysis of the dynamic system stability. The results of breeding gain measurements, which demonstrated conclusively the superiority of plutonium as a fuel, have been treated elsewhere. (4) The results of a stability analysis, based essentially on transfer function and power coefficient measurements, constitute the subject of this report.

\section{REVIEW OF STABILITY CONSIDERATIONS IN SMALL FAST SYSTEMS}

To appreciate why stability may be a problem in small, concentrated fast systems, such as EBR-I, it is necessary to examine those features 
peculiar to this reactor type. Since the chain reaction is perpetuated with unmoderated fission neutrons, the prompt-neutron lifetime is short. Insofar as operational stability is concerned, the short prompt-neutron lifetime is of little consequence, since the delayed critical kinetic behavior of an operating system depends solely on the half-lives and the relative apportionment of delayed-neutron-emitting species. Since fast and thermal systems are characterized by essentially the same delayed-neutron parameters, their kinetic behaviors, in the absence of feedback, are similar. The short lifetime does become a distinguishing feature if the region of prompt criticality is inadvertently reached. Excellent reviews of the consequences of prompt critical bursts in fast systems have been given by McCarthy (5) and Okrent.(6)

On a more practical basis, the most important feature distinguishing fast and thermal systems is the nature of the power coefficient. In a thermal system, for example a boiling water reactor, the net power coefficient is most strongly influenced by density changes in the moderator. The effects of fuel and structural expansions are of secondary importance.

In a small fast system, the converse is true. Density changes in the coolant, usually $\mathrm{Na}$ or $\mathrm{NaK}$, are reflected by reactivity changes which are relatively small. By far, most of the power coefficient is associated with the expansion of fuel and, in special cases, certain structural features. For a thermal system, in which the fuel is considerably more dilute, small movements of fuel material have little effect on reactivity. In a fast system, fuel movements of the order of mils are important, particularly if the driving force is coupled through a transport lag with the thermal output. It follows that structural features completely acceptable from the viewpoint of stability in thermal systems may actually lead to serious instability effects in a small, highly concentrated core.

To understand the mechanism of instability, it is convenient to regard the reactor as a simple reactivity amplifier. At levels of power for which heating effects are negligible, the gain of the system is completely described in terms of the delayed-neutron parameters and the schedule of reactivity insertion. For all fast systems of practical interest, the prompt generation time is without effect on the kinetic behavior. At levels of power for which sensible nuclear heating occurs, a reactivity input leads to changes in power and temperature which, in turn, are manifested by changes in the density of fuel, coolant, and structure. All such changes are sensed by the system as reactivity perturbations which act to modify the input. Reactivity insertions initiated by the system itself as the result of density or dimensional changes are commonly referred to as feedback.

Since the expansion processes in the fuel, coolant, and structure require a finite amount of time, there is always a phase lag between the input and feedback reactivities. The reactor cannot distinguish between the various reactivities, and its response for a given insertion schedule is dictated by the neutron kinetic equations and the vectorial sum of the reactivity 
components. If the feedback is entirely prompt and negative, a portion of the reactivity input will be cancelled by the feedback. The reactor, sensing reactivity as a vectorial sum, interprets the partial cancellation as a reduction in input. Under these circumstances, the reactor will be stable for all credible reactivity insertions regardless of schedule. If the power coefficient is prompt and positive, as indeed it can be, the feedback will reinforce the input. Such a system may be stable, conditionally stable, or unstable, depending on the magnitude of the power coefficient, the frequency dependence of the feedback, and the power.

The fact that the overall power coefficient is strongly negative does not, by itself, guarantee stability. It is essential that its time response be prompt. If the feedback is delayed sufficiently in time, strong shifts in phase between input and feedback reactivities may occur. Under these special, but not improbable, conditions, constructive interference between reactivity "waves" will occur. Reactivity insertions and withdrawals will be amplified and manifested by an increase in the overall system gain.

The extent to which strong time-dependent feedbacks can influence the stability of a system is well-illustrated by the kinetic behaviors of the first two EBR-I loadings, commonly known as Mark I and Mark II. (7) In both cases there was a decided tendency for the power to oscillate whenever the reactor was operated at ratios of power to coolant flow rate greater than those specified for normal operation. Usually some initiating influence, such as a control rod adjustment or a change of flow rate, was needed to initiate the oscillation. On certain more striking occasions, the oscillations appeared to be spontaneous in origin. (7)

As the result of intensive studies, the origin of the instability was attributed to the combination of two major power coefficient components: one prompt and positive, and the other negative, larger in magnitude, and strongly delayed. $(8-12)$ The mechanism responsible for the positive component was eventually identified as the inward bowing of fuel rods during a power increase. The origin of the delayed negative effect was traced to an upper structural member which controlled reactivity through delayed expansion effects. As an important consequence of these studies, it was firmly established that those features responsible for the instability were mechanical in origin, rather than nuclear, and could be eliminated through elementary changes in design.

For the near future at least, it seems likely that the concern for the stability of small fast systems will diminish for the following reasons: the reassuring conclusions resulting from various EBR-I experiments, and the fact that future commercial fast systems will be less sensitive to structurally connected feedbacks. On the other hand, a shift in emphasis to small, concentrated systems for space application may, in the future, rekindle an interest in the stability of such systems. As the results of Mark-IV experiments show, many poorly defined effects strongly influence the magnitude and linearity of 
the net power coefficient. Included among these are the effects of differential material expansion, clearance systems, and the bowing, saturation, and hang-up of individual fuel slugs. Complications from such sources seriously limit the interpretation of transfer function data as a function of power. Failure to consider such effects in the design stage of small-core, high-power-density space systems could very well be a serious oversight. As a more immediate consequence, the results of the Mark-IV stability experiments suggest the possibility of hitherto unsuspected feedback mechanisms in EBR-II and, in addition, point out the need for further study in regard to the FARET experimental program. (13) The results of the Mark-IV studies illustrate the problems involved and suggest additional areas of investigation. 


\section{TRANSFER FUNCTION MEASUREMENTS}

\section{A. Description of the Mark-IV Loading}

Since the Mark-IV loading of EBR-I has been described in detail elsewhere,(14) only those features which have an immediate bearing on the kinetics of the system will be discussed here. An idealized vertical cross section through the inner tank assembly and reflector (lead in this case) is given in Fig. 1. Eight regions, each significantly different in material composition, are shown. Each is radially symmetric with respect to the vertical axis.

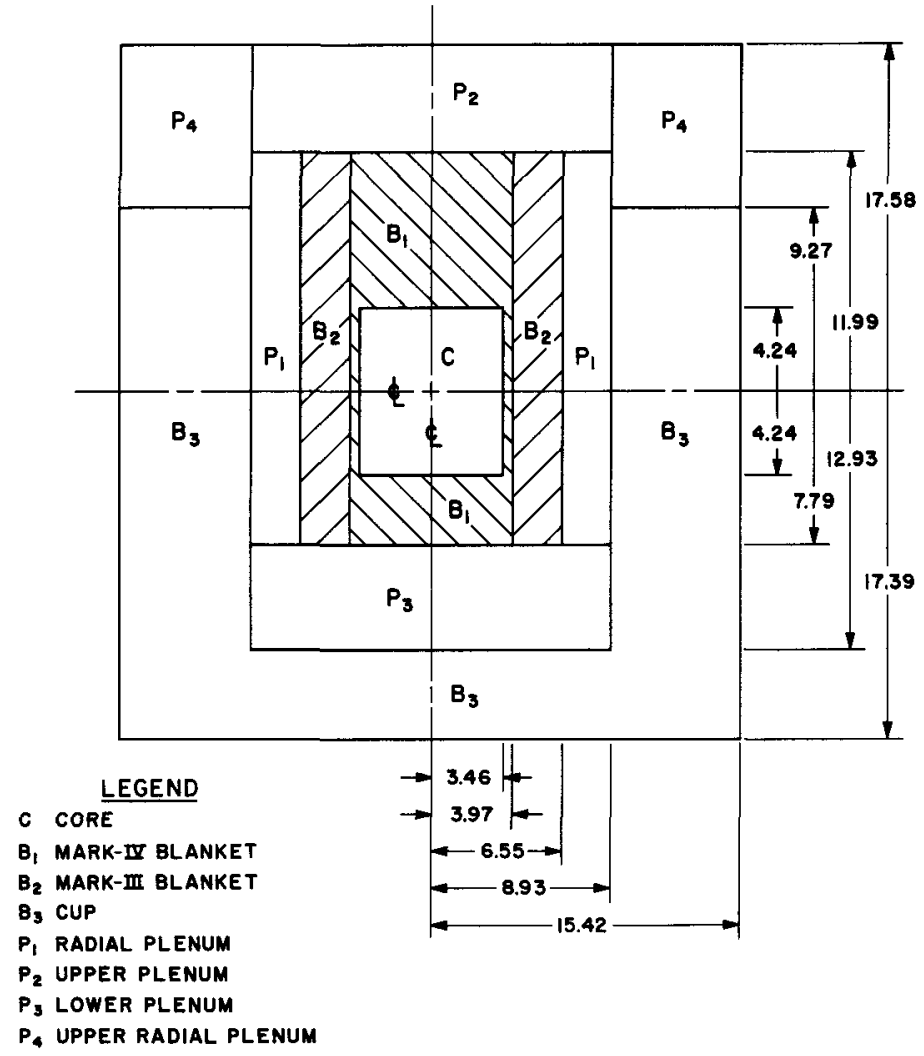

Fig. 1. Vertical Cross Section through EBR-I, Mark IV

A summary of the physical composition of each region is given in Table I. The cited plutonium content of $35.3 \mathrm{v} / \mathrm{o}$ for the core refers to the fuel alloy which has the following composition (w/o): $\mathrm{Pu}, 98.59$; $\mathrm{Al}, 1.25$; impurities, 0.16. Isotopically, the plutonium content of the fuel material may be broken down as follows: $\mathrm{Pu}^{239}, 94.44 ; \mathrm{Pu}^{240}, 5.06 ; \mathrm{Pu}^{241}, 0.49 ; \mathrm{Pu}^{238}$ and $\mathrm{Pu}^{242}$, a trace. The cold wet (NaK) critical mass corrected for control elements amounted to $27.79 \mathrm{~kg}$ plutonium (all isotopes). 
Table I

MARK-IV CORE AND BLANKET COMPOSITION (v/o)

(See Fig. 1)

\begin{tabular}{|c|c|}
\hline Region & Composition \\
\hline C, Core & 304 SS, 6.3; Al bronze, 0.5; Zircaloy-2, 21.1; NaK, 36.7; and Pu, 35.3. \\
\hline $\begin{array}{l}\mathrm{B}_{1}, \text { Mark-IV } \\
\text { Blanket }\end{array}$ & 304 SS, 6.3; Al bronze, 0.5; Zircaloy-2, 21.1 ; NaK, 36.6; and depleted U, 35.4. \\
\hline $\begin{array}{l}\mathrm{B}_{2}, \text { Mark-III } \\
\text { Blanket }\end{array}$ & 304 SS, 7.3; NaK, 25.6; natural U, 48.9; and Zr, 18.2. \\
\hline $\mathrm{B}_{3}$, Cup & $304 \mathrm{SS}, 4.36 ;$ and lead, 85.1 \\
\hline $\begin{array}{l}P_{1}, \text { Radial } \\
\text { Plenum }\end{array}$ & $304 \mathrm{ss}, 54.1 ; \mathrm{Al}, 5.44 ; \mathrm{NaK}, 12.97 ;$ and Inconel, 2.84. \\
\hline $\begin{array}{l}P_{2} \text {, Upper } \\
\text { Plenum }\end{array}$ & 304 SS, 71.5; and $\mathrm{NaK}, 22.2$ \\
\hline $\begin{array}{l}P_{3} \text {, Lower } \\
\text { Plenum }\end{array}$ & $304 \mathrm{SS}, 27.1 ; \mathrm{Al}, 4.91 ; \mathrm{NaK}, 35.4$; Inconel, 2.21 ; and $\mathrm{Zr}, 3.45$ \\
\hline $\begin{array}{l}P_{4} \text {, Upper } \\
\text { Radial Plenum }\end{array}$ & 304 SS, 75. \\
\hline B. Oscillat & r Rod and Drive System \\
\hline
\end{tabular}

The device used for producing a sinusoidal variation of reactivity consists of a longitudinal, $\mathrm{B}_{4}^{10} \mathrm{C}$-filled hole drilled slightly off center in a stainless steel rod. The $\mathrm{B}_{4}^{10} \mathrm{C}$ column, approximately $3 \mathrm{in}$. in length and $\frac{5}{8}$ in. in diameter, consists of a train of individual slugs. The stainless steel rod, $\frac{15}{16} \mathrm{in}$. in diameter, is located in a $1 \frac{1}{16}-\mathrm{in}$. thimble which, in turn, is positioned in the radial breeding blanket approximately 2 in. from the edge of the fuel-blanket interface. Accordingly, the $\mathrm{B}_{4}^{10} \mathrm{C}$ column is located in a region in which the gradient of the neutron flux is steep. Rotation of the rod is manifested by an alternate insertion and withdrawal of the poison column with respect to the core, and is sensed by the system as a sinusoidally varying input of reactivity.

Studies of the reactivity wave-shape were carried out by measuring the stable reactor period as a function of the angular position of the oscillator rod. The results of experiments carried out in both ZPR-III and EBR-I indicated, within the limits of experimental accuracy, the absence of a significant harmonic content. $(11,15)$ The peak-to-peak reactivity worth of the rod was measured to be 16.7 Ih.

The oscillator rod drive unit consists of a $\frac{1}{2}-\mathrm{hp}$ controlled-speed motor connected through reduction gears to the oscillator rod drive shaft which, in turn, extends downward through a packing gland in the reactor top and is supported by a bearing in the reactor support structure. The oscillator rod is suspended from the drive shaft and is positioned by sleeve-type 
guide bearings located along and at the bottom of the surrounding thimble. The drive unit is capable of rotating the oscillator rod over a frequency range of 0.001 to 20 cycles/sec.

C. Null Balance Method

A block diagram illustrating the components and the principle of the null balance system is given in Fig. 2. The variable-speed drive, in addition to rotating the oscillator rod, drives a cosine potentiometer through a variable phase coupler which, in turn, is controlled by a geared selsyn motor. The selsyn motor, manually adjustable by a crank, is connected electrically to a selsyn transmitter which acts as a phase indicator. The actual phase relationship between the oscillator rod and the cosine potentiometer is readable through a revolution counter connected directly to the crank of the selsyn motor. The high gear ratio of the selsyn system permits accurate readings of the phase.

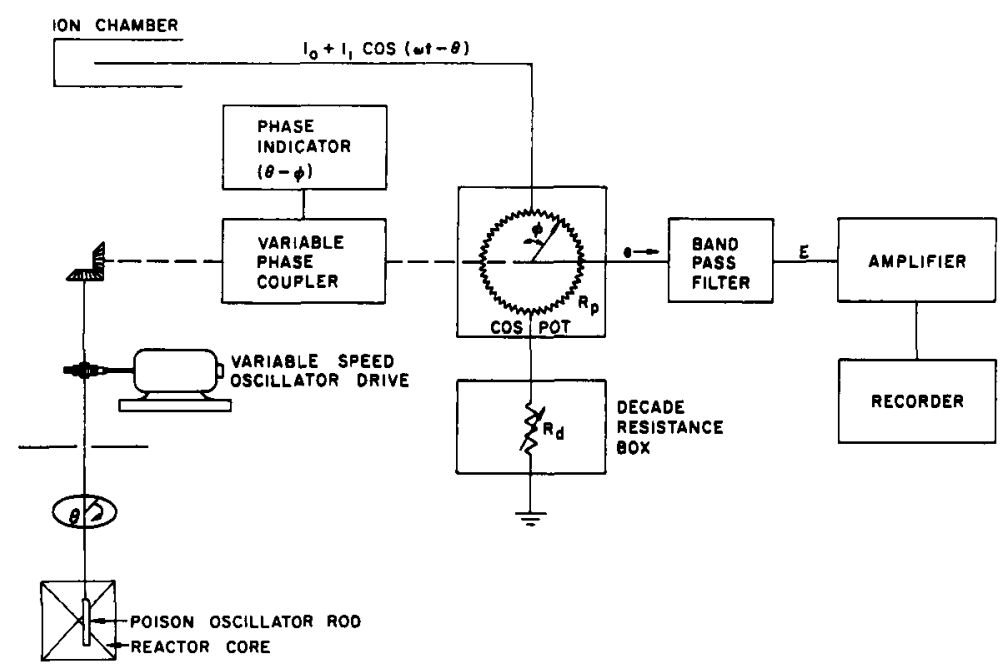

Fig. 2. Oscillator Scheme for EBR-I

The current from the ion chamber passes through the cosine potentiometer and decade resistance box in series. The voltage signal appearing at the wiper of the cosine potentiometer is filtered by the band pass filter, amplified, and displayed on an oscillographic recorder. The filter blocks the $\mathrm{dc}$ component of the input voltage and attenuates components which are higher and lower in frequency than the fundamental. The filter has an attenuation characteristic of $24 \mathrm{db} /$ octave.

Assuming that the reactivity input varies sinusoidally and that the basic kinetic equations may be linearized by dropping the products of small differentials, the method is easily susceptible to mathematical development. Hence, the current output of the ionization chamber may be described as 


$$
i=I_{0}+I_{1} \cos (\omega \tau-\theta)
$$

where $\theta$ is the angle between the reactivity input function and the ionization chamber response, and $\omega$ is the oscillation frequency. The cosine potentiometer generates a resistance with a half-amplitude of

$$
R_{p}=\frac{1}{2} R[1-\cos (\omega \tau-\phi)]
$$

where $R$ is the maximum resistance of the potentiometer and $\phi$ is the phase angle between the cosine potentiometer and the oscillator rod. The voltage output of the cosine potentiometer, e, is then

$$
e=i\left(R_{p}+R_{d}\right)
$$

where $R_{d}$ is the resistance of the decade box.

By substitution,

$$
\begin{aligned}
e & =\left\{\frac{1}{2} R[1-\cos (\omega \tau-\phi)]+R_{d}\right\}\left[I_{0}+I_{1} \cos (\omega \tau-\phi)\right] \\
= & I_{0}\left(R_{d}+\frac{1}{2} R\right)-\frac{1}{2} I_{0} R \cos (\omega \tau-\phi)+\frac{1}{2} I_{1} R \cos (\omega \tau-\phi) \\
& +I_{1} R_{d} \cos (\omega \tau-\theta)-\frac{1}{2} I_{1} R \cos (\omega \tau-\theta) \cos (\omega \tau-\phi) .
\end{aligned}
$$

Since the dc term is eliminated in the filter and since the cosine product term is highly attenuated, the output voltage from the filter is simply

$$
E=I_{1}\left(R_{d}+\frac{1}{2} R\right) \cos (\omega \tau-\theta)-\frac{1}{2} I_{0} R \cos (\omega \tau-\phi)
$$

When the decade box is adjusted so that $E=0$, the amplitude ratio between $I$ and $I_{0}$ is

$$
\frac{I_{1}}{I_{0}}=\frac{R \cos (\omega \tau-\phi)}{\left(R_{d}+\frac{1}{2} R\right) \cos (\omega \tau-\theta)}=\frac{\Delta n}{n}
$$

where $\Delta \mathrm{n} / \mathrm{n}$ is the fractional change in neutron level resulting from the oscillating reactivity input. By adjustment of the variable phase coupler such that $\theta=\phi$,

$$
\frac{\Delta \mathrm{n}}{\mathrm{n}}=\frac{\mathrm{R}}{\mathrm{R}_{\mathrm{d}}+\frac{\mathrm{l}}{2} \mathrm{R}}
$$


and since the overall transfer function $G$ is defined as

$$
\mathrm{G}(\mathrm{i} \omega)=\frac{1}{\rho_{\text {in }}} \frac{\Delta \mathrm{n}}{\mathrm{n}}
$$

where $\rho_{\text {in }}$ is the oscillating reactivity input, the amplitude may be evaluated directly from resistance data at the null point. Hence, the gain is given by

$$
\left|G_{0}(i \omega)\right|=\frac{R}{\rho_{\text {in }}\left(R_{d}+\frac{1}{2} R\right)} .
$$

The phase of the transfer function, $\theta$, is simply the angle $\phi$ established under null conditions.

In practice, it is difficult to establish an absolute null point. To locate the null position as closely as possible, it is necessary to establish by trial and error a combination of phase coupler and decade resistance box settings which give an approximate minimum in the voltage $E$. Then, holding one variable constant, the other is varied about the null. A plot of the voltage output versus the variable setting then leads by extrapolation to an acceptably accurate null setting. It is, of course, necessary to repeat the procedure with the other variable fixed. The results of experience have shown that under normal circumstances, phase and amplitude data are reproducible within the limits of $\pm 1^{\circ}$ and $\pm 1 \%$, respectively.

D. Zero Power Transfer Function

In the absence of temperature-sensitive reactivity feedback effects, i.e., for the case in which nuclear heating is negligible, the kinetic response of the reactor is dictated completely by the delayed-neutron parameters and the effective prompt-neutron lifetime. The development of the necessary mathematics is well understood and has been treated in detail elsewhere. (16) The expression for the transfer function is

$$
G_{0}(i \omega)=\frac{\Delta n}{n \rho_{i n}}=\frac{1}{i \omega \ell^{*}\left[1+\sum_{i=1}^{6} \frac{\beta_{i}}{\ell^{*}\left(\lambda_{i}+i \omega\right)}\right]}
$$

where $\Delta \mathrm{n} / \mathrm{n}$ is the fractional change in power orginating from a sinusoidally varying reactivity $\rho_{i n}, \omega$ is the oscillation frequency, $l^{*}$ is the effective prompt-neutron lifetime, and $\beta_{i}$ and $\lambda_{i}$ are, respectively, the relative abundance and decay constant for the $i^{\text {th }}$ delayed-neutron-emitting group. If $\ell^{*}$, $\beta_{i}$, and $\lambda_{i}$ are known, $G_{0}(i \omega)$ may be evaluated as a function of frequency from Eq. 11 . 
For a thermal system, nearly all fissions occur in the primary fuel, and since $\ell^{*}, \beta_{i}$, and $\lambda_{i}$ are reasonably well known, the evaluation of $G_{0}(i \omega)$, while tedious, is straightforward. For a fast reactor, particulary for EBR-I, Mark IV, an evaluation of $G_{0}(i \omega)$ is complicated by the fact that fissions occur in several species, namely, $\mathrm{Pu}^{239}, \mathrm{Pu}^{240}, \mathrm{U}^{235}$, and $\mathrm{U}^{238}$. Since the delayedneutron parameters differ for each species, it is necessary to establish a set of effective $\beta_{i}^{\prime}$ s and $\lambda_{i}$ 's which describe the average properties of the delayed-neutron-emitting isotopes. As an additional complication, the relative worths of neutrons (both prompt and delayed) emitted as the result of fission in each species must also be considered. Since $\mathrm{Pu}^{239}$ and $\mathrm{Pu}^{240}$ fissions are limited to the core, while $U^{235}$ and $U^{238}$ fissions are limited to the blanket regions, an evaluation of the relative worths of prompt and delayed neutrons involves a spatial weighting.

Such an evaluation has been carried out by Loewenstein, who has determined the relative number of fissions for each species and the relative worths of prompt and delayed neutrons for a three-region system consisting of a core and two surrounding blankets of different densities. (17) The calculations were carried out for idealized spherical geometry, with consideration given to the fact that the usual uranium reflector in EBR-I was replaced by one of lead. The partition of fission events between the various species and the relative worths of prompt-and delayed-neutron events are summarized in Table II. Using the information of Table II and values of $\beta_{i}$ for the various species, (18) Loewenstein has also evaluated the effective delay fractions for each species and for each of the six delayed-neutron-emitting groups. His results are summarized in Table III. Summation over all groups for each of the four species results in an overall effective delayedneutron fraction of 0.00304 .

\section{Table II}

RELATIVE WORTHS OF PROMPT AND DELAYED NEUTRONS FOR IDEALIZED THREE-REGION MARK-IV SYSTEM

(Radial Sphere with Lead Cup)

\begin{tabular}{|c|c|c|c|c|}
\hline & Species & $\begin{array}{c}\text { Relative Number } \\
\text { of Fissions }\end{array}$ & $\begin{array}{c}\text { Relative Worth of } \\
\text { Delayed Events }\end{array}$ & $\begin{array}{l}\text { Relative Worth of } \\
\text { Prompt Events }\end{array}$ \\
\hline \multirow[t]{2}{*}{ Core } & $\mathrm{Pu}^{239}$ & 0.8122 & 1.037 & 1.00 \\
\hline & $\mathrm{Pu}^{240}$ & 0.0244 & 1.0418 & 1.0046 \\
\hline \multirow[t]{2}{*}{ B- 1} & $\mathrm{U}^{235}$ & 0.0004 & 0.6538 & 0.6666 \\
\hline & $\mathrm{U}^{238}$ & 0.0246 & 0.6548 & 0.6680 \\
\hline \multirow[t]{2}{*}{$B-2$} & $\mathrm{U}^{235}$ & 0.0109 & 0.3278 & 0.3563 \\
\hline & $\mathrm{U}^{239}$ & 01294 & 0.3413 & 0.3699 \\
\hline
\end{tabular}


Table III

$\beta_{\text {eff }}$ FOR EBR-I, MARK IV

(Radial Sphere with Lead Cup)

\begin{tabular}{|c|c|c|c|c|c|c|}
\hline Isotope & $\begin{array}{c}\beta_{\text {eff }} \\
\text { Group 1 } \\
\end{array}$ & $\begin{array}{c}\beta_{\text {eff }} \\
\text { Group } 2 \\
\end{array}$ & $\begin{array}{c}\beta_{\text {eff }} \\
\text { Group } 3 \\
\end{array}$ & $\begin{array}{c}\beta_{\text {eff }} \\
\text { Group } 4 \\
\end{array}$ & $\begin{array}{c}\beta_{\text {eff }} \\
\text { Group } 5 \\
\end{array}$ & $\begin{array}{c}\beta_{\text {eff }} \\
\text { Group } 6 \\
\end{array}$ \\
\hline $\mathrm{Pu}^{239}$ & 0.00007462580 & 0.0005498740 & 0.0004245630 & 0.0006443260 & 0.00020199500 & 0.00006873430 \\
\hline $\mathrm{Pu}^{240}$ & 0.00000207608 & 0.0000202475 & 0.0000142303 & 0.0000259510 & 0.00000949636 & 0.00000215023 \\
\hline $\mathrm{U}^{235}$ & 0.00000089128 & 0.0000049977 & 0.0000044095 & 0.0000095479 & 0.00000300222 & 0.00000060983 \\
\hline $\mathrm{U}^{238}$ & 0.00001277350 & 0.0001346850 & 0.0001592300 & 0.0003814510 & 0.00022121900 & 0.00007376050 \\
\hline Total & 0.00009036660 & 0.0007098050 & 0.0006024330 & 0.0010612800 & 0.00043571200 & 0.00014522500 \\
\hline
\end{tabular}

Effective values of $\lambda_{i}$ were established by weighting each value for a given species and a given delay group by the fraction of fissions occurring for that particular species. The effective parameters for delayedneutron emission are summarized in Table IV.

Table IV

EFFECTIVE DELAYED-NEUTRON PARAMETERS

FOR EBR-I, MARK IV

\begin{tabular}{|c|c|c|}
\hline Neutron Group & $\lambda_{i}, \sec ^{-1}$ & $\beta_{i}$ \\
\hline 1 & 0.01294 & 0.0000904 \\
\hline 2 & 0.03125 & 0.0007098 \\
\hline 3 & 0.1345 & 0.0006024 \\
\hline 4 & 0.3348 & 0.0010613 \\
\hline 5 & 1.286 & 0.0004357 \\
\hline \multirow[t]{2}{*}{6} & 3.361 & 0.0001452 \\
\hline & & 0.00304 \\
\hline
\end{tabular}

E. Calculated Zero Power Transfer Function

The zero power transfer function $G_{0}(i \omega)$ was evaluated as a function of frequency from Eq. 11 with an IBM-1620.(19) Input data consisted of values given for $\beta_{i}$ and $\lambda_{i}$ in Table IV and a value of $4 \times 10^{-8} \mathrm{sec}$ for the effective prompt-neutron lifetime. (14)

The results for both phase and amplitude are given by the solid curves of Fig. 3. At low frequencies, the amplitude increases and approaches infinity as the oscillation frequency approaches zero. For frequencies in the vicinity of 1.0 to 10.0 cycles/sec, the amplitude decreases slowly with increasing frequency and approaches on asymptotic limit of $1 / \beta$ eff. The phase shift approaches a limiting value of $-90^{\circ}$ as the oscillation frequency approaches zero, whereas at high frequencies, 1.0-10.0 cycles/sec, the lag approaches zero. 


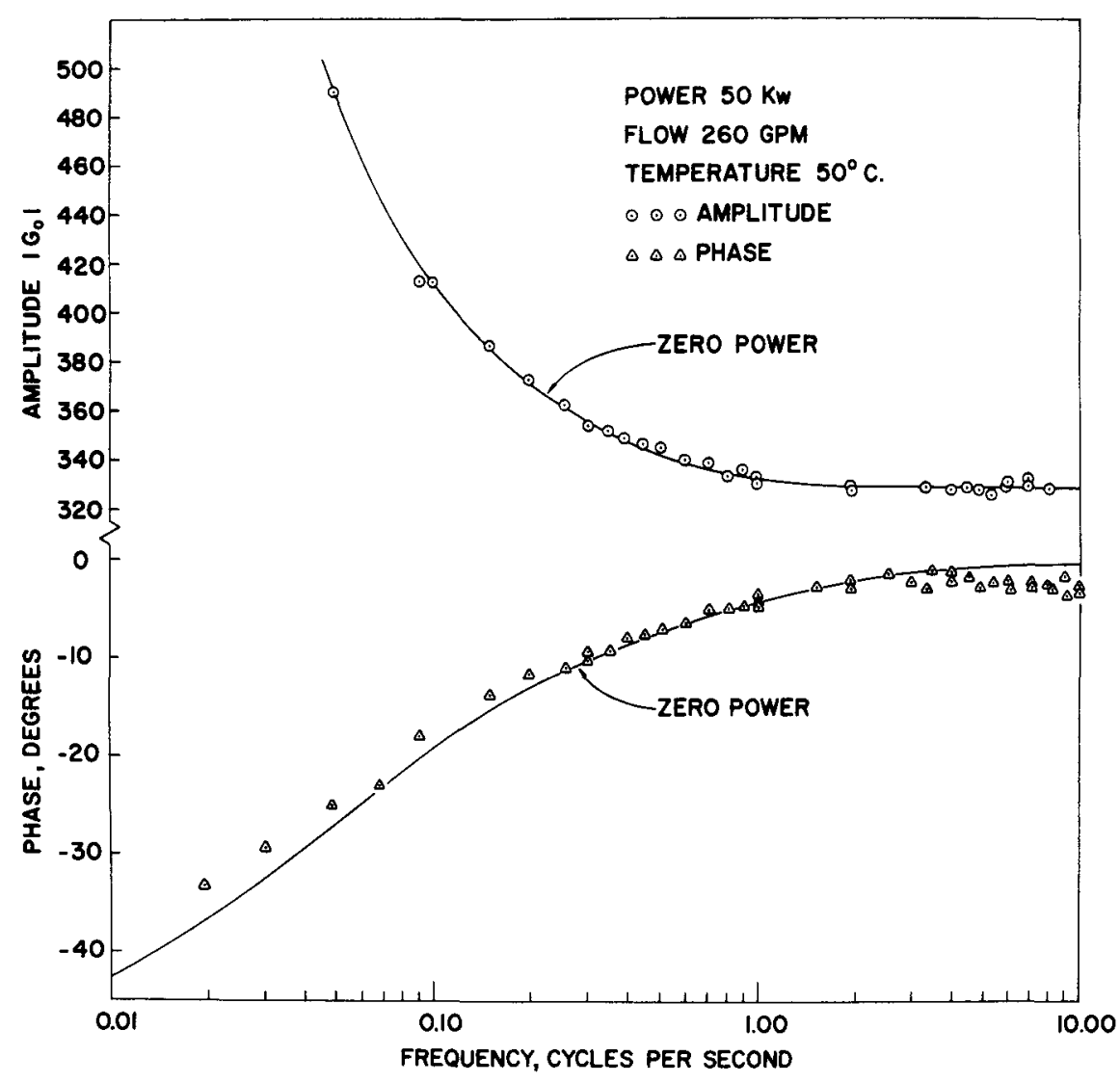

Fig. 3. Zero Power Transfer Function

F. Experimental Zero Power Transfer Function

In principle it is possible to evaluate the amplitude at any given frequency from a knowledge of $\rho_{i n}$, the oscillating reactivity driving function, and $\Delta \mathrm{n} / \mathrm{n}$, which is established from the resistance settings under null conditions. A value for the driving function may be established directly by measuring the difference in reactivity noted with the oscillator rod in its maximum and minimum worth positions through period measurements. However, the errors associated with determining $\rho_{\text {in }}$ in this manner are somewhat larger than the reproducibility of null measurements. Furthermore, experience has shown(li) that the worth of the oscillator rod in EBR-I varies as much as $2-3 \%$, depending on the reactor power and the coolant temperature. To avoid these difficulties and to eliminate errors associated with independent measurements of $\rho_{\text {in }}$, all amplitude data were normalized to the zero power amplitude curve for frequencies greater than 2.0 cycles/sec. Essentially, the normalization amounts to an indirect determination of the driving function worth from the expression

$$
\left|G_{0}(i \omega)\right|=\frac{R}{\rho_{i n}\left(R_{d}+\frac{1}{2} R\right)},
$$


where $\left|G_{0}(i \omega)\right|$ is the calculated zero power value of the amplitude at a given high frequency, and $R$ and $R_{d}$ are the resistance values of the cosine potentiometer and decade box, respectively. The successful application of the method relies on the validity of the assumption that feedback effects at high frequencies, i.e., greater than 2.0 cycles/sec, are negligible. In view of previous experimental results $(11)$ under a wide variety of experimental conditions, this assumption appears to be valid. The measured value of $|G(i \omega)|$, either with or without feedback, may then be found from the expression

$$
|G(i \omega)|=\frac{M}{\left(R_{d}+\frac{1}{2} R\right)}
$$

where $M$ is an average value of the product $\left|G_{0}(i \omega)\right|\left(R_{d}+\frac{l}{2} R\right)$ evaluated at several high frequencies.

As a consequence of the normalization, a rather exact agreement is forced between experimentally measured and calculated values of amplitude at higher frequencies. Accordingly, an agreement between experimental and calculated values is essentially worthless as a criterion of equipment and method reliability. At lower frequencies, however, the fit is not forced, and the agreement between experimentally measured and calculated values may satisfactorily be used as a reliability criterion. From the low-frquency amplitude results, given in Fig. 3 , it seems reasonable to conclude that experimental values of the amplitude are consistent with theoretically derived values.

For frequencies greater than 2 cycles/sec, a significant difference exists between experimentally measured and calculated values for the phase of the transfer function. It is also apparent from Fig. 3 that as the frequency increases, the magnitude of the discrepancy becomes larger. The results of previous experiments(15) in which the discrepancy between measured and calculated phase values was established as a function of detector distance, demonstrated that as the detector is moved away from the core, the discrepancy at a given frequency increases. Covering the detector with $0.030 \mathrm{in}$. of cadmium foil decreased the discrepancy. Accordingly, the phase discrepancies at high frequency have been associated with the time required for neutrons originating in the core to reach the detector.

From earlier studies, conducted by means of EBR-I simulation with ZPR-III, (15) it is also apparent that the extent of the discrepancy depends on the type of detector used. Such a discrepancy, for a given high frequency, is insensitive to power, and, once established, may be used as a correction for other data sets. Furthermore, the region of discrepancy, i.e., $>2.0 \mathrm{cycles} / \mathrm{sec}$, is of little practical interest since feedback effects at the se frequencies are essentially nonexistent. 
At low frequencies, measured values of the phase are consistently less negative than calculated values. In fact, a definite trend may be noted in the low-frequency phase region with the sense of the discrepancy such that its magnitude increases at the lower frequencies. The origin of these discrepancies has not been established. One obvious explanation, for example, concerns the failure to evaluate properly the effective values of $\beta_{i}$ and $\lambda_{i}$ used in calculations of the zero power transfer function.

In separating the feedback from transfer function measurements, it becomes necessary to choose between the two sets of reference phase data. Since discrepancies of this nature were not experienced in earlier studies conducted with the same equipment, and since the calculated values were based on a series of approximations, it was believed that feedback separations should be based on experimentally determined values of $\left|G_{0}(i \omega)\right|$ and $\phi_{0}$.

\section{G. Transfer Function Measurements at Power}

The approach to full power (nominally $1200 \mathrm{~kW}$ ) from cold clean critical was carried out in the following sequence: 510,878 , and $1193 \mathrm{~kW}$. Following each incremental change in power, a complete set of measurements of transfer function was carried out. In general, oscillation frequencies ranged from 0.02 to 10.0 cycles/sec. Amplitude data were normalized to calculated values for frequencies greater than 2.0 cycles/sec, while phase data were normalized to measured zero power values for the same frequency range. After each power increase, flow change tests in which the power level was monitored during and after a sudden flow change (approximately 30\%) were conducted in an effort to detect the existence of a prompt positive power coefficient component.

To study the effects of coolant inlet temperature on the kinetics of the system, measurements of the transfer function were carried out at inlet temperatures ranging from a low of $50^{\circ} \mathrm{C}$ to a high of $230^{\circ} \mathrm{C}$. Because of a limit placed on the maximum fuel temperature $\left(450^{\circ} \mathrm{C}\right)$ it was not possible to operate at full power under conditions of high inlet temperature. The highest power level reached for an inlet temperature of $230^{\circ} \mathrm{C}$ was only $930 \mathrm{~kW}$. Nevertheless, sufficient information was obtained to permit a limited anlaysis of the effects of inlet temperature.

A summary of all pertinent transfer function data is given in Table V. All data sets were taken under series flow condition, and with all tightening rods and core clamps tightened. 
Table V

SUMMARY OF TRANSFER FUNCTION DATA

\begin{tabular}{|c|c|c|c|}
\hline $\begin{array}{l}\text { Run } \\
\text { No. }\end{array}$ & $\begin{array}{c}\text { Frequency, } \\
\mathrm{c} / \mathrm{sec} \\
\end{array}$ & $\begin{array}{c}\text { Amplitude } \\
\mathrm{G}\end{array}$ & $\begin{array}{c}\text { Phase } \\
\phi\end{array}$ \\
\hline & $510 \mathrm{~kW}$, & $\mathrm{pm}, 50^{\circ} \mathrm{C}$ & \\
\hline 79 & 3.00 & 323.8 & -2.9 \\
\hline 80 & 4.10 & 332.0 & -3.9 \\
\hline 81 & 5.00 & 329.9 & -2.2 \\
\hline 82 & 6.00 & 327.6 & -2.2 \\
\hline 83 & 7.00 & 330.3 & -2.5 \\
\hline 84 & 8.00 & 328.7 & -2.5 \\
\hline 85 & 9.00 & 328.7 & -2.5 \\
\hline 86 & 10.00 & 328.0 & -2.9 \\
\hline 87 & 0.708 & 336.6 & -3.9 \\
\hline 88 & 0.396 & 352.4 & -6.7 \\
\hline 89 & 0.200 & 376.5 & -8.0 \\
\hline 90 & 0.100 & 400.3 & -9.6 \\
\hline 91 & 0.075 & 401.4 & -11.1 \\
\hline 92 & 0.050 & 429.6 & -15.5 \\
\hline 93 & 0.020 & 530.9 & -20.9 \\
\hline 94 & 0.150 & 389.2 & -9.8 \\
\hline 95 & 0.150 & 876.6 & -9.5 \\
\hline 96 & 0.120 & 392.2 & -9.3 \\
\hline 97 & 0.090 & 401.4 & -10.8 \\
\hline
\end{tabular}

$878 \mathrm{~kW}, 281 \mathrm{gpm}, 51^{\circ} \mathrm{C}$

$\begin{array}{rllr}98 & 9.47 & 328.7 & -3.4 \\ 99 & 5.00 & 326.6 & -1.8 \\ 100 & 2.54 & 331.8 & -1.9 \\ 101 & 1.68 & 330.8 & -2.6 \\ 102 & 1.00 & 332.0 & -3.4 \\ 103 & 0.58 & 338.4 & -4.4 \\ 104 & 0.35 & 361.3 & -6.4 \\ 105 & 0.20 & 381.2 & -5.0 \\ 106 & 0.102 & 358.3 & -2.4 \\ 107 & 0.069 & 365.1 & -4.2 \\ 108 & 0.0400 & 372.3 & -9.6 \\ 109 & 0.0199 & 429.4 & -15.4 \\ 110 & 0.247 & 370.8 & -6.0 \\ 111 & 0.170 & 380.0 & -3.8 \\ 112 & 0.125 & 370.8 & -1.2\end{array}$


Table V (Contd.)

\begin{tabular}{|c|c|c|c|}
\hline \multirow[t]{2}{*}{$\begin{array}{l}\text { Run } \\
\text { No. }\end{array}$} & $\begin{array}{c}\text { Frequency, } \\
\mathrm{c} / \mathrm{sec} \\
\end{array}$ & $\begin{array}{c}\text { Amplitude } \\
\text { G }\end{array}$ & $\begin{array}{c}\text { Phase } \\
\phi\end{array}$ \\
\hline & \multicolumn{2}{|c|}{$1193 \mathrm{~kW}, 286 \mathrm{gpm}, 73^{\circ} \mathrm{C}$} & \\
\hline 113 & 1.74 & 330.0 & -2.2 \\
\hline 114 & 3.07 & 329.2 & -2.2 \\
\hline 115 & 5.44 & 327.5 & -2.9 \\
\hline 116 & 8.33 & 327.3 & -3.4 \\
\hline 117 & 1.72 & 332.1 & -2.1 \\
\hline 118 & 1.00 & 333.7 & -3.3 \\
\hline 119 & 0.59 & 340.1 & -3.7 \\
\hline 120 & 0.338 & 366.6 & -4.3 \\
\hline 121 & 0.193 & 382.5 & +3.5 \\
\hline 122 & 0.150 & 359.4 & +5.2 \\
\hline 123 & 0.120 & 343.6 & +4.7 \\
\hline 124 & 0.109 & 331.9 & +5.2 \\
\hline 125 & 0.070 & 318.1 & +2.0 \\
\hline 126 & 0.041 & 309.1 & -3.3 \\
\hline 127 & 0.028 & 342.6 & -8.2 \\
\hline \multirow[t]{2}{*}{128} & 0.253 & 374.6 & -1.8 \\
\hline & \multicolumn{2}{|c|}{$1120 \mathrm{~kW}, 291 \mathrm{gpm}, 174^{\circ} \mathrm{C}$} & \\
\hline 129 & 1.01 & 329.9 & -2.1 \\
\hline 130 & 2.03 & 330.8 & -1.7 \\
\hline 131 & 0.88 & 331.0 & -1.9 \\
\hline 132 & 0.694 & 334.3 & -2.8 \\
\hline 133 & 0.487 & 345.1 & -4.2 \\
\hline 134 & 0.292 & 377.0 & -3.5 \\
\hline 135 & 0.147 & 386.2 & +7.0 \\
\hline 136 & 5.93 & 329.5 & -2.4 \\
\hline 137 & 5.06 & 328.7 & -2.5 \\
\hline 138 & 3.00 & 330.4 & -1.7 \\
\hline 139 & 0.244 & 363.2 & -2.5 \\
\hline 140 & 0.170 & 398.1 & +3.4 \\
\hline 141 & 0.127 & 369.1 & +7.4 \\
\hline 142 & 0.200 & 392.1 & +2.3 \\
\hline 143 & 0.100 & 330.1 & +8.7 \\
\hline 144 & 0.070 & 302.5 & +8.7 \\
\hline 145 & 0.050 & 284.6 & +3.9 \\
\hline 146 & 0.020 & 296.0 & -3.2 \\
\hline
\end{tabular}


Table V (Contd.)

\begin{tabular}{lccc}
$\begin{array}{l}\text { Run } \\
\text { No. }\end{array}$ & $\begin{array}{c}\text { Frequency, } \\
\mathrm{c} / \mathrm{sec}\end{array}$ & $\begin{array}{c}\text { Amplitude } \\
\mathrm{G}\end{array}$ & $\begin{array}{c}\text { Phase } \\
\phi\end{array}$ \\
\cline { 2 - 3 } & \multicolumn{2}{c}{$\begin{array}{c}930 \mathrm{~kW}, 294 \\
\text { gpm, 230 }\end{array}$} & \\
154 & 5.82 & 329.3 & \\
155 & 4.90 & 328.5 & -1.9 \\
156 & 4.05 & 329.1 & -2.4 \\
157 & 2.01 & 328.3 & -2.0 \\
158 & 1.00 & 328.5 & -2.0 \\
159 & 0.89 & 331.8 & -3.0 \\
160 & 0.70 & 335.3 & -3.6 \\
161 & 0.50 & 341.1 & -4.5 \\
162 & 0.296 & 373.4 & -6.0 \\
163 & 0.251 & 390.6 & -6.9 \\
164 & 0.200 & 410.3 & -6.4 \\
165 & 0.170 & 408.8 & -3.9 \\
166 & 0.150 & 409.4 & +0.2 \\
167 & 0.129 & 402.5 & +1.6 \\
168 & 0.100 & 377.4 & +4.0 \\
169 & 0.070 & 345.5 & +4.9 \\
170 & 0.049 & 301.3 & +3.6 \\
171 & 0.020 & 319.3 & +0.5 \\
& & & -2.6
\end{tabular}

A comparison of results for the various data sets is given in Figs. 4 through 8. From Figs. 4, 5, and 6, which compare the results for low values of inlet temperature, it is apparent that increases in power tend to make the system less stable. The extent by which experimental values of the amplitude lie above calculated zero power values may be used as a criterion of constructive interference between the input and feedback reactivities. At $510 \mathrm{~kW}$ and $50^{\circ} \mathrm{C}$, a slight increase in the experimental amplitude (in the vicinity of 0.1 to $0.3 \mathrm{cycle} / \mathrm{sec}$ ) may be seen in Fig. 4 . At $878 \mathrm{~kW}$ and at essentially the same inlet temperature, $51^{\circ} \mathrm{C}$, a definite "bump" appears in the amplitude curve (see Fig. 5). A strong phase increase, i.e., less negative, is also noted in the vicinity of 0.1 to 0.2 cycle/sec. Finally, at full power, $1193 \mathrm{~kW}$ and at a slightly higher inlet temperature, $73^{\circ} \mathrm{C}$, the "bump" is even more prominent (see Fig. 6). The corresponding phase values reflect the increase in power by becoming even less negative; in fact, they become positive in the vicinity of 0.07 to 0.15 cycle/ $/ \mathrm{sec}$.

The effect of inlet temperature on the transfer function is illustrated qualitatively by a comparison of the data set at $1193 \mathrm{~kW}$ and $73^{\circ} \mathrm{C}$ with the data set at $1120 \mathrm{~kW}$ and $175^{\circ} \mathrm{C}$. Although in going from 73 to $175^{\circ} \mathrm{C}$ the power level actually decreases, the associated feedback change is such that the amplitude peak increases and phase values become even more positive. 


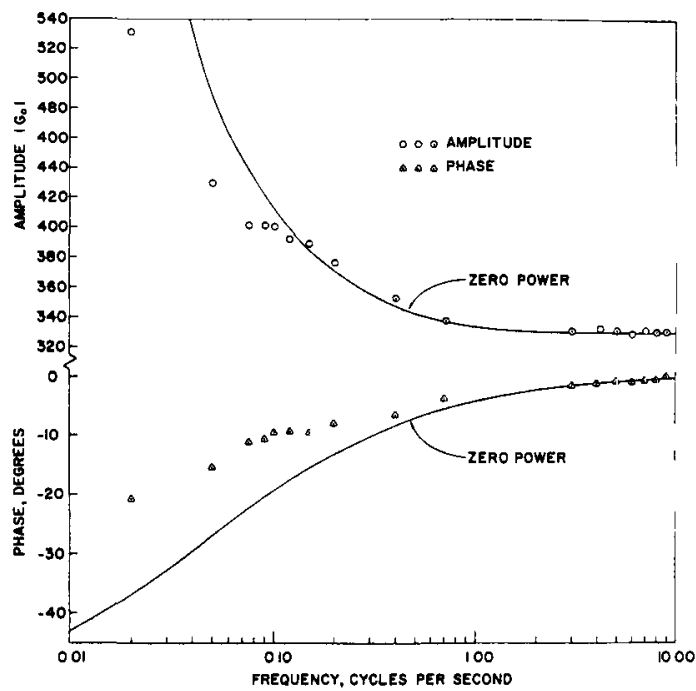

Fig. 4

Load Power Transfer Function for $510 \mathrm{~kW}, 265 \mathrm{gpm}$, and $50^{\circ} \mathrm{C}$

Fig. 5

Load Power Transfer Function for $878 \mathrm{~kW}, 281 \mathrm{gpm}$, and $51^{\circ} \mathrm{C}$
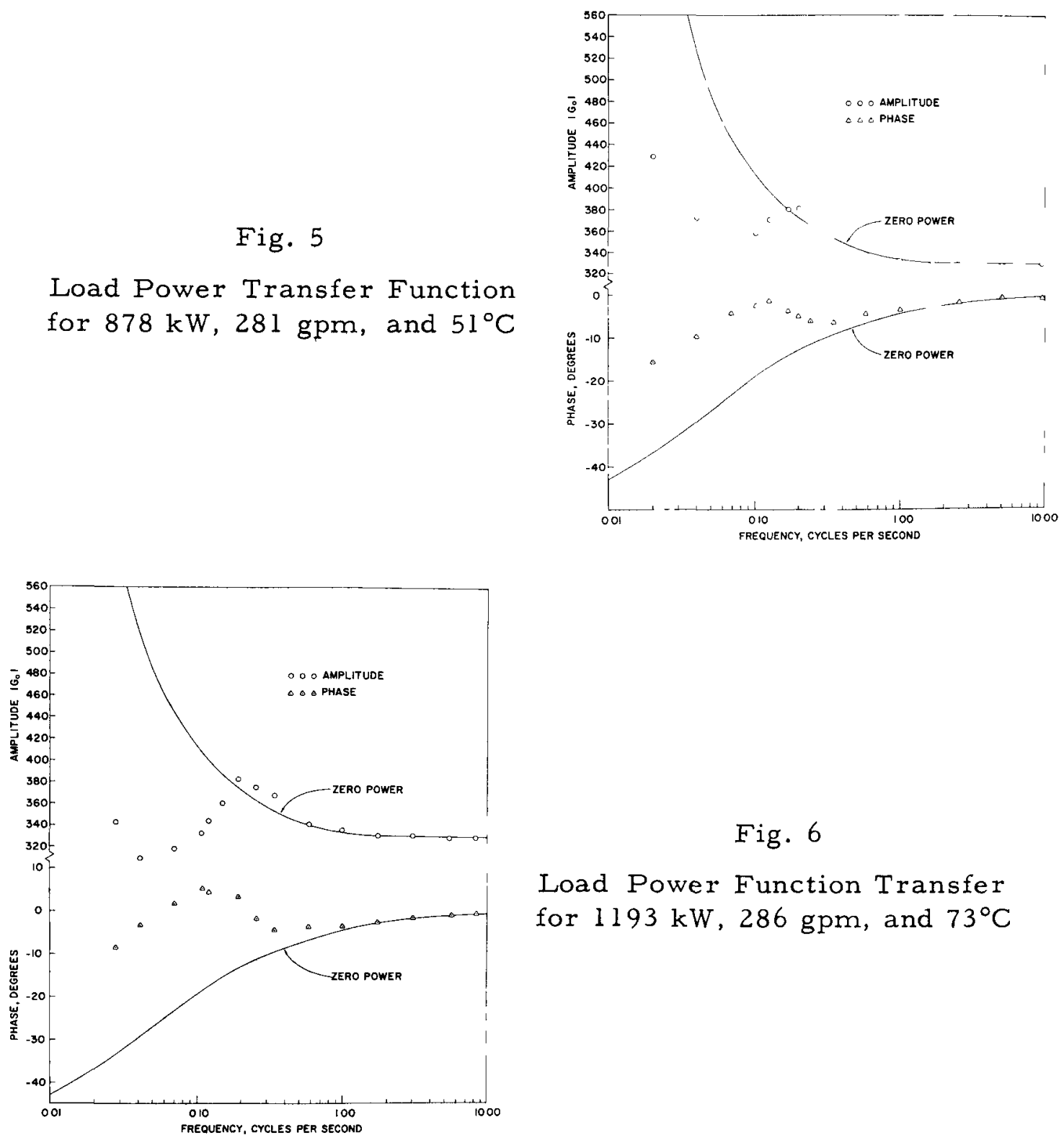

Fig. 6

Load Power Function Transfer for $1193 \mathrm{~kW}, 286 \mathrm{gpm}$, and $73^{\circ} \mathrm{C}$ 


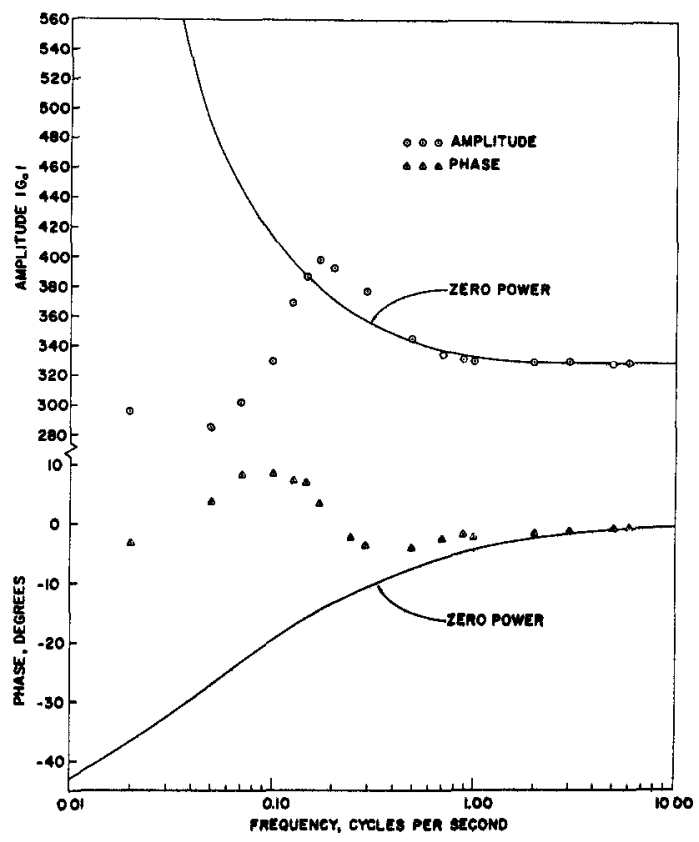

Fig. 7

Load Power Transfer Function for $1120 \mathrm{~kW}, 29 \mathrm{lgpm}$, and $175^{\circ} \mathrm{C}$

Fig. 8

Load Power Transfer Function for $930 \mathrm{~kW}, 294 \mathrm{gpm}$, and $230^{\circ} \mathrm{C}$

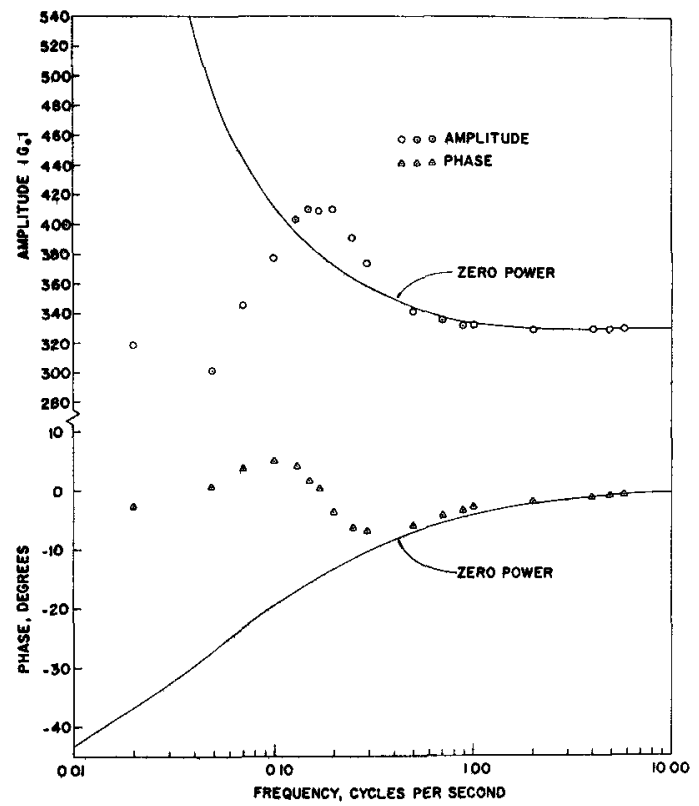




\section{RESULTS AND ANALYSIS}

\section{A. Feedback Separation}

Physically, it is difficult to place more than a qualitative interpretation on transfer function results alone. It is more instructive to separate the reactivity feedback from the transfer function and to interpret the feedback in terms of basic time constants and power coefficients.

From basic servomechanical considerations, the transfer function is defined as

$$
G(i \omega)=\frac{G_{0}(i \omega)}{1+G_{0}(i \omega) H(i \omega)},
$$

where $G(i \omega)$ is the transfer function under power conditions, $G_{0}(i \omega)$ is the zero power transfer function, and $\mathrm{H}(\mathrm{i} \omega)$ is the reactivity feedback. A rearrangement of Eq. (14) leads to

$$
H(i \omega)=[1 / G(i \omega)]-\left[1 / G_{0}(i \omega)\right]
$$

where $1 / G(i \omega)$ and $1 / G_{0}(i \omega)$ are the corresponding inverse gains. It is a simple matter then to evaluate $H(i \omega)$ since $1 / G(i \omega)$ is readily established from the experimental results and $1 / G_{0}(i \omega)$ is available from the calculated zero power data.

Each of the data sets given in Table $\mathrm{V}$ and illustrated in Figs. 4 through 8 was processed to give the resultant feedback The results of the various separations are summarized in Table VI. In addition to the real and imaginary components of the feedback, the associated amplitude and phase are also listed.

A graphical comparison of the various feedback results is given in Fig. 9, in which the real and imaginary components are plotted as a function of frequency. Since each data set was obtained under different conditions of power, flow, and temperature, it is difficult to as ign any immediate quantitative significance to the results illustrated. Nevertheless, the data, taken collectively, indicate significant trends. The fact that the feedback enters the third quadrant (lower left-hand quadrant) at high frequencies indicates that any credible feedback model must be characterized by at least two poles, i.e., two frequency-dependent terms in the denominator. The obvious increase of feedback with power is expected on a purely mathematical basis since feedback is defined as the product of power and the power coefficient of reactivity. Although not particularly obvious from Fig. 9, a strong temperature sensitivity exists. For example, the amplitude of the feedback for $930 \mathrm{~kW}$ and $230^{\circ} \mathrm{C}$ is consistently greater than the amplitude established at $1193 \mathrm{~kW}$ and $73^{\circ} \mathrm{C}$. A detailed discussion of temperature-sensitive feedback effects is given in Sections IV-G and IV-H. 
Table VI

SUMMARY OF REACTIVITY FEEDBACK SEPARATIONS

\begin{tabular}{|c|c|c|c|c|c|c|c|}
\hline $\begin{array}{l}\text { Frequency, } \\
\text { c/sec }\end{array}$ & Feedback $\mathrm{H} \times 10^{3}$ & $\begin{array}{c}\text { Feedback } \\
\text { Amplitude } \times 10^{3}\end{array}$ & $\begin{array}{l}\text { Feedback } \\
\text { Phase, deg }\end{array}$ & $\begin{array}{l}\text { Frequency, } \\
\text { c/sec }\end{array}$ & Feedback $\mathrm{H} \times 10^{3}$ & $\begin{array}{c}\text { Feedback } \\
\text { Amplitude } \times 10^{3}\end{array}$ & $\begin{array}{l}\text { Feedback } \\
\text { Phase, deg }\end{array}$ \\
\hline \multicolumn{4}{|c|}{$510 \mathrm{~kW}, 265 \mathrm{gpm}, 51^{\circ} \mathrm{C}$} & \multicolumn{4}{|c|}{$1120 \mathrm{~kW}, 291 \mathrm{gpm}, 175^{\circ} \mathrm{C}$} \\
\hline 0.020 & $(0.535-0.126 \mathrm{i})$ & 0.552 & 13.2 & 0.020 & $(2.140-0.6191)$ & 2.230 & 16.2 \\
\hline 0.050 & $(0.377-0.228 \mathrm{i})$ & 0,441 & 31.2 & 0.050 & $(1.639-1.089 i)$ & 1.966 & 33.6 \\
\hline 0.075 & $(0.302-0.305 i)$ & 0.429 & 45.3 & 0.070 & $(1.160-1.305 i)$ & 1.745 & 48.4 \\
\hline 0.090 & $(0.196-0.286 i)$ & 0.347 & 55.6 & 0.100 & $(0.674-1.188 \mathrm{i})$ & 1.366 & 53.8 \\
\hline 0.100 & $(0.152-0.311 i)$ & 0.346 & 63.9 & 0.127 & $(0.235-1.015 i)$ & 1.042 & 77.0 \\
\hline 0.120 & $(0.106-0.270 i)$ & 0.290 & 68.5 & 0.147 & $(0.064-0.947 \mid)$ & 0.950 & 86.1 \\
\hline 0.150 & $(0.029-0.199 i)$ & 0.201 & 81.7 & 0.170 & $(-0.064-0.740 i)$ & 0.744 & 95.0 \\
\hline 0.200 & $(0.000-0.180 \mathrm{i})$ & 0.180 & 90.0 & 0.200 & $(-0.080-0.652 i)$ & 0.658 & 97.0 \\
\hline 0.396 & $(-0.040-0.040 \mathrm{i})$ & 0.0566 & 135.0 & 0.244 & $(0.042-0.372 i)$ & 0.375 & 83.5 \\
\hline \multirow[t]{4}{*}{0.708} & $(0.013-0.055 i)$ & 0.0564 & 103.4 & 0.290 & $(-0.117-0.286 i)$ & 0.309 & 111.2 \\
\hline & & & & 0.490 & $(-0.005-0.1181)$ & 0.118 & 92.5 \\
\hline & \multirow{2}{*}{\multicolumn{2}{|c|}{$878 \mathrm{~kW}, 281 \mathrm{gpm}, 51^{\circ} \mathrm{C}$}} & & 0.690 & $(0.031-0.1131)$ & 0.117 & 74.7 \\
\hline & & & & 0.880 & $(0.050-0.119 i)$ & 0.129 & 67.5 \\
\hline 0.020 & $(1.014-0.180 \mathrm{i})$ & 1.028 & 10.0 & & & & \\
\hline 0.040 & $(0.928-0.432 i)$ & 1.024 & 25.0 & \multicolumn{4}{|c|}{$930 \mathrm{~kW}, 294 \mathrm{gpm}, 230^{\circ} \mathrm{C}$} \\
\hline 0.069 & $(0.640-0.601 i)$ & 0.878 & 43.2 & & & & \\
\hline 0.102 & $(0.465-0.601 i)$ & 0.760 & 52.3 & 0.020 & $(1.901-0.6541)$ & 2.010 & 19.0 \\
\hline 0.125 & $(0.270-0.617 i)$ & 0.674 & 66.2 & 0.049 & $(1.471-0.875 i)$ & 1.715 & 30.7 \\
\hline 0.170 & $(0.068-0.417 \mathrm{i})$ & 0.423 & 80.9 & 0.070 & $(0.790-0.980 \mathrm{i})$ & 1.260 & 51.2 \\
\hline 0.200 & $(-0.020-0.313 i)$ & 0.313 & 93.7 & 0.100 & $(0.325-0.915 i)$ & 0.970 & 70.5 \\
\hline 0.247 & $(-0.023-0.209 i)$ & 0.211 & 96.3 & 0.129 & $(0.030-0.838 \mathrm{i})$ & 0.838 & 88.0 \\
\hline 0.350 & $(-0.070-0.097 i)$ & 0.120 & 102.6 & 0.150 & $(-0.067-0.694 i)$ & 0.696 & 95.5 \\
\hline \multirow[t]{4}{*}{0.580} & $(0.020-0.0601)$ & 0.063 & - & 0.170 & $(-0.115-0.601 i)$ & 0.612 & 100.8 \\
\hline & & & & 0.200 & $(-0.200-0.384 i)$ & 0.433 & 117.6 \\
\hline & \multirow{2}{*}{\multicolumn{2}{|c|}{$1193 \mathrm{~kW}, 286 \mathrm{gpm}, 73^{\circ} \mathrm{C}$}} & & 0.251 & $(-0.171-0.2031)$ & 0.265 & 130.0 \\
\hline & & & & 0.296 & $(-0.128-0.128 \mathrm{i})$ & 0.182 & 135.0 \\
\hline 0,028 & $(1.450-0.418 \mathrm{i})$ & 1.510 & 16.1 & 0.500 & $(0.018-0.014 i)$ & 0.023 & - \\
\hline 0.070 & $(1.040-0.915 i)$ & 1.385 & 41.3 & 0.700 & $(0.022-0.071)$ & 0.074 & - \\
\hline 0.109 & $(0.650-0.973 i)$ & 1.170 & 56.3 & 0.890 & $(0.030-0.029 i)$ & 0.042 & - \\
\hline 0.120 & $(0.495-0.940 i)$ & 1.062 & 62.3 & & & & \\
\hline 0.150 & $(0.255-0.878 \mathrm{i})$ & 0.914 & 73.8 & & & & \\
\hline 0.193 & $(0.000-0.400 i)$ & 0.400 & 90.0 & & & & \\
\hline 0.253 & $(-0.050-0.405 i)$ & 0.405 & 97.0 & & & & \\
\hline 0.340 & $(-0.092-0.2051)$ & 0.207 & 114.2 & & & & \\
\hline 0.590 & $(0.003-0.907 i)$ & 0.097 & - & & & & \\
\hline
\end{tabular}

\section{FEEDBACK $\times 10^{-3}$}

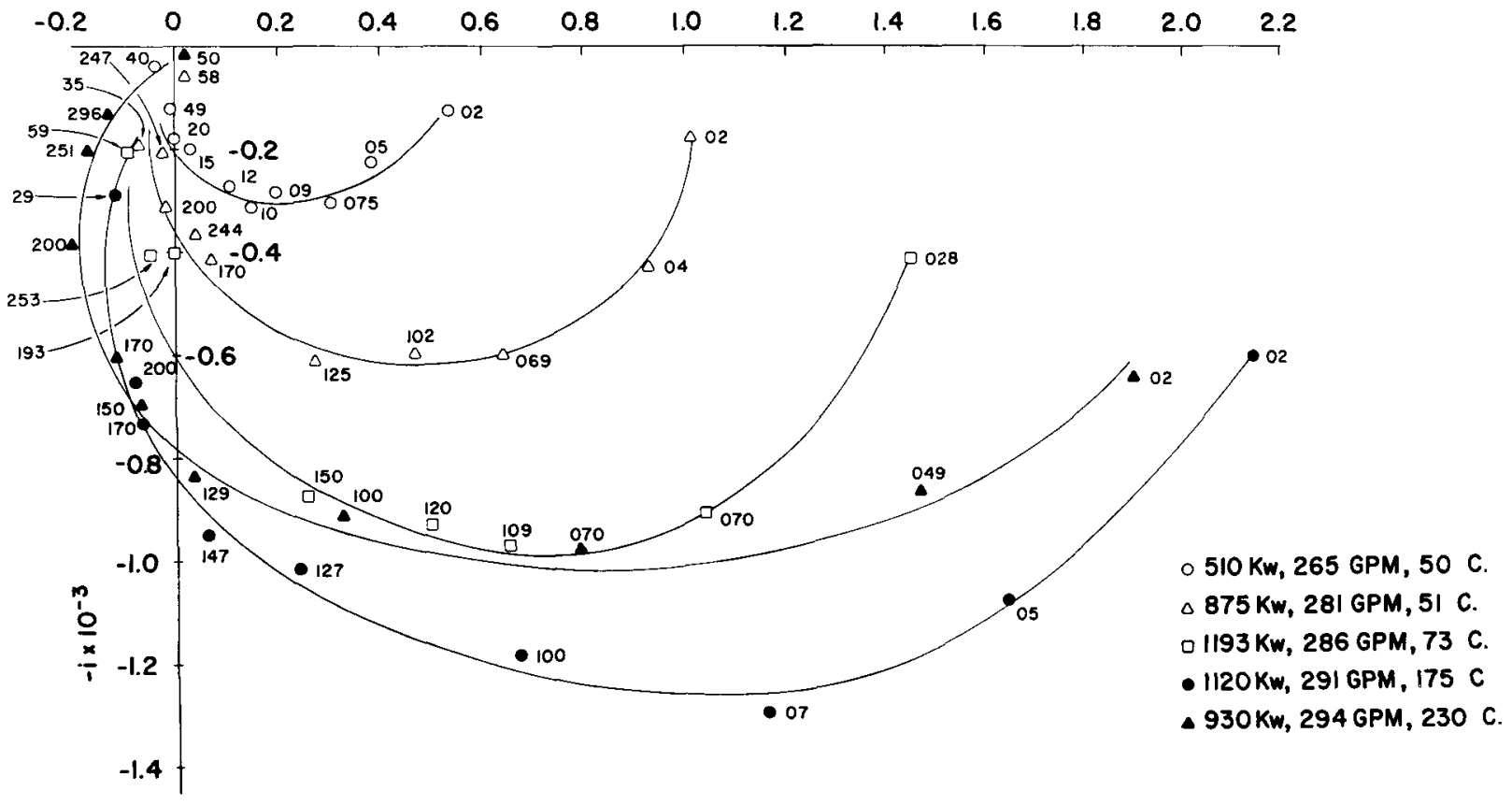

Fig. 9. Comparison of Feedback 
B. Feedback Model

The ultimate achievement of feedback analysis would be a detailed, yet understandable, mathematical model which explains all experimentally observed kinetic phenomena for all conditions of power, coolant flow rate, and temperature. This, of course, is the goal of many analysts, particularly those who are assigned the responsibility of predicting the kinetic characteristics of a system for which no experimental information exists. $(20,21)$

The usual approach, in such instances, is one of synthesis. Anticipated reactivity-feedback effects are incorporated into a credible feedback model which is based, to some extent, on intuition. The substitution of estimates for power coefficients, time constants, damping parameters, etc., into the mathematical model leads eventually to a frequency-dependent feedback which permits an advanced evaluation of the system stability. How well the predicted results agree with those established experimentally is not known, but it is reasonable to assume that the original prediction is not perfect. Once experimental information is available, the analyst can return to his synthesis, and by shaping various parameters, force a better agreement between calculated and experimental results. The degree of forcing necessary to effect a satisfactory agreement may then be used as a measure of how well the model was conceived and how accurately the initial parametric values were estimated. For a satisfactory agreement, the analyst believes, with some justification, that he understands the origins of the various feedbacks, their magnitudes, and their relative phasing. This direct or synthetic approach enjoys the distinct advantage that potentially deleterious features in an unbuilt system may be detected early enough to permit their elimination in the final design. In a practical sense, the synthetic approach requires a scrutiny of features which conceivably could be dangerous and which could be innocently carried over to the final design.

The most important limitation imposed on the synthetic, preoperational stability analysis is one of failing either to understand or to anticipate fundamental feedback mechanisms which eventually turn out to be important. For example, it seems unlikely that even a highly skilled analyst would have anticipated the difficulties experienced with $\mathrm{SRE}^{(22)}$ or with the earlier loadings of EBR-I. (12)

For extremely small, highly concentrated cores, such as the Mark-IV loading of EBR-I, factors beyond the control and the ability of the analyst combine to limit the usefulness of the direct approach. From the results of many measurements, $(11,12)$ including those discussed in this report, it is clear that the feedback is strongly dependent on intangibles such as clearances between fuel rods, between fuel rods and hexes, and even between hexes. Each of these clearance systems is dependent on temperature, and since jacket and hex material differ, considerations must be given to 
the different thermal expansion properties of the materials involved. Accordingly, the treatment of clearance systems on an exact or quantitative basis, over a wide range of power and temperature conditions, is not a wellestablished science.

As an effective compromise, the analyst may in such situations accept the experimental data, and by working backwards attempt to associate the various feedbacks with temperature-dependent physical processes. In other words, feedback data resulting from a specified set of operating conditions may be broken down into basic time constants and power coefficient, each of which, hopefully, may be identified with a specific feedback mechanism. Finally, if the values of empirically determined parameters are consistent with those expected from theoretical considerations, the analyst may then feel justified in accepting a mathematical model which describes the feedback function for a limited range of operating conditions.

The feedback associated with the Mark-IV loading may be described by a model which includes two general terms:

$$
\text { Total Feedback = Prompt Feedback + Delayed Feedback, }
$$

in which the first term defines the feedback associated primarily with power density changes in the fuel, and the second term describes the feedback associated with expansion effects in the cladding, coolant, and structure. On a relative basis, the first term is prompt and the second term is delayed. The model is essentially that proposed by Kinchin,(8) and later extended by Bethe $(9)$ and by Smith et al.,(12) to describe the feedback as sociated with earlier EBR-I loadings.

\section{Prompt Term}

Contributing to the first term on the right-hand side of Eq. (16) are the following physical effects: (a) expansion of fuel, (b) NaK expulsion, (c) radial expansion of the jackets, (d) slug bowing, and (e) jacket bowing.

\section{a. Axial Expansion of the Fuel}

One immediate effect of a power increase is manifested by a volumetric expansion of the fuel material. The density of fuel nuclei, i.e., the number of fuel atoms per cubic centimeter of fuel material, decreases and reactivity is lost. Obviously, there are two associated components: one axial and the other radial, both of which act with essentially the same relaxation time. Insofar as reactivity changes are concerned, the axial expansion effect is by far the larger since the physical change in core height reflects an integral expansion of the entire column of fuel. Since each fuel slug is completely uncoupled radially with respect to its 
nearest neighbor, fuel expansion effects do not integrate across the diameter of the core. As a result, the corresponding change in the core radius is small. There is, of course, an integral movement imparted to the slugs by the radial expansion of the jackets. Such an effect is more properly considered as a consequence of jacket expansion and is treated as such below.

\section{b. NaK Expulsion}

During a power increase, NaK from the heat transfer bond is physically displaced from the annulus. Since the linear expansion coefficient for the fuel is larger than that for the jackets (12.5 versus $9.6 \mathrm{x}$ $\left.10^{-6} \Delta \mathrm{L} / \mathrm{L} /{ }^{\circ} \mathrm{C}\right)$, the volume of the annulus decreases. The effect is further accented by a disproportionate temperature increase in the fuel. As an additional factor, the density of the NaK decreases. All such effects are negative and all are prompt. Each acts along a time base comparable with that followed by the fuel.

\section{c. Radial Expansion of the Jackets}

The effects of a power increase are manifested almost immediately as an increase in the diameter of the Zircaloy-2 jackets. If physical contact between individual fuel slugs and the jackets be assumed, it follows that jacket expansion results in a net outward movement of fuel. Since the jackets are radially coupled through a system of longitudinal ribs, the radial movement of fuel at the periphery reflects an integration of expansion effects across the diameter of the core. Clearance systems, however, must be conducive to an integral effect. If clearances between rods and between rods and hexes do not exist, a constraining action will tend to limit the extent of expansion. If, on the other hand, clearances are so large that jackets expand independently, the benefits of a radial integration are lost. As discussed in Section IV-G, the clearance situation is such that strong radial expansion effects are likely.

The time base along which jacket expansion proceeds is not simple. In the immediate vicinity of the core, expansion effects will be prompt. At the top of the upper blanket, however, jacket expansion effects are considerably delayed since a finite amount of time is required for the propagation of the coolant-temperature signal initiated by a power increase. As discussed in Section IV-B-2, the effect of upper jacket expansion is not small and contributes significantly to the delayed radial feedback term.

\section{d. Slug Bowing}

The imposition of a strong radial temperature gradient across a given fuel slug is manifested by a bowing action which tends to move fuel towards a region of higher worth, i.e., towards the vertical axis of symmetry. Such effects are, of course, positive and prompt. A detailed discussion of slug-bowing effects is given in Section IV-E. 


\section{e. Jacket Bowing}

The location of a fuel rod in a strong flux gradient may, under certain circumstances, lead to a limited amount of jacket bowing. Coolant channels on sides closer to the core will run hotter than those directly opposite. As a consequence, the preferential expansion of the inner surface will be manifested in the form of a bow which tends to move the jacket (and fuel) into a region of higher worth. Although the system of tightening rods and ribs is designed to prevent rod-bowing, the existence of small clearances between fuel rods can, under special conditions, permit a limited degree of bowing. In principle, the action of the tighteningrod system should eliminate, or at least greatly reduce, clearances between fuel rods and between fuel rods and hexes. In practice clearances do exist. Since the rod system is tightened at room temperature, the effect of operating at an elevated inlet temperature is one tending to loosen the core. Stainless steel structural components (hexes and support rings) expand at a rate approximately twice that of the jackets. Such effects are discussed in detail in Section IV-G.

While rod-bowing effects are possible, it is curious to note that the associated reactivity effect may be positive, negative, or even zero. As outlined previously, $(11,12)$ a positive rod-bowing effect is a special consequence of radial restraint at upper and lower contact points, conditions which are not easily realized. Whether rod-bowing effects are positive or negative in Mark IV depends on clearances between rods, between rods and hexes, and between rod tips and locating holes. Insofar as the present analysis is concerned, the sign of the effect is primarily of academic interest since jacket-bowing reactivity effects, both prompt and delayed, are algebraically superimposed on the respective radial expansion components.

If jacket-bowing effects exist, it seems likely the associated time base will be described by a relatively prompt component for jacket material in the vicinity of the core and a somewhat delayed component for jacket material located at a distance downstream.

\section{Delayed Term}

The second term on the right-hand side of Eq. (16) includes reactivity feedback effects resulting from the following physical processes.

\section{a. NaK Expulsion}

While the expulsion of $\mathrm{NaK}$ from the heat transfer annulus is essentially prompt, a somewhat longer time is required to change the $\mathrm{NaK}$ concentration throughout the core and upper blanket. The loss of $\mathrm{NaK}$ from these regions following a power increase has two origins: one, a decrease in density, and the other, an expulsion through the physical reduction 
of available volume. In other words, jackets and structural components expand to displace a volume previously occupied by $\mathrm{NaK}$. The time base along which $\mathrm{NaK}$ expulsion proceeds is complicated by the existence of two components: one corresponding to the prompt radial expansion of jackets, and the other corresponding to the delayed expansion of materials downstream from the core. The first of these is inseparable from the prompt radial expansion effect discussed in Section IV-B-1, and its effects are reflected in the first term on the right-hand side of Eq. (16). Similarly, delayed effects are included as an inseparable component in the second term on the right-hand side of Eq. (16).

\section{b. Radial Expansion of the Jackets}

Clearly, the reactivity effects associated with the radial expansion of jackets in the vicinity of the upper blanket are negative, and since a finite time is required for a temperature signal originating in the core to reach this region, the effects are also delayed. Furthermore, as Storrer(23) has shown, the time required for transmission of a temperature signal in the $\mathrm{NaK}$ coolant is not the physical transit time between two points. Rather, the effective transport time is the physical transit time multiplied by the ratio of the total heat capacity of the system (in the blanket region) divided by the heat capacity of the coolant. An evaluation of this ratio for the upper blanket region gave a value of 10 . The effective transport time between core center and the upper portion of the blanket at fuel flow is then the physical transit time, $0.28 \mathrm{sec}$, multiplied by 10 , or $2.8 \mathrm{sec}$.

\section{c. Jacket Bowing}

For precisely the reasons outlined in the immediate section above, reactivity-feedback effects resulting from the bowing of jackets in the vicinity of the upper blanket will be delayed. Since such effects act essentially along the time base for radial expansion, the two effects, radial expansion and bowing, add algebraically.

\section{d. Structural Expansion}

Eventually, the temperature of the hexes comes to equilibrium with the temperature of the coolant following a power increase. If small clearances between hexes exist, the hexes will tend to expand and to allow fuel rods, held under an outward driving force, to move outward. Such effects are delayed and, of course, negative.

\section{Mathematical Description of the Prompt Term}

Each of the reactivity effects included in the first term on the right-hand side of Eq. (16) is either prompt or involves a prompt component. To be strictly correct, each effect along with its characteristic time constant 
and feedback amplitude should be considered individually. The result would be an extremely unwieldly series of feedback components, one not easily interpretable in terms of basic physical processes. If this approach is taken, the first term on the right-hand side of Eq. (16) alone would involve as many as five different feedback components and five different time constants. Any attempt to resolve each of these parameters from experimental feedback data (which are poorly defined in the high-frequency region) would be impossible. Fortunately, some of the five prompt effects are relatively small, some pair off and tend to cancel algebraically, and others are characterized by essentially the same time constant. Hence, the prompt term of Eq. (16) may be reduced to the following:

$$
H=\frac{A_{f}}{1+i \omega \tau_{f}}+\frac{A_{a}}{\left(1+i \omega \tau_{f}\right)\left(1+i \omega \tau_{a}\right)}+\frac{A_{j}}{\left(1+i \omega \tau_{f}\right)\left(1+i \omega \tau_{a}\right)\left(1+i \omega \tau_{j}\right)},
$$

where the gain constants $A_{f}, A_{a}$, and $A_{j}$ appearing in the numerators are the zero-frequency feedback amplitudes for fuel expansion, NaK expulsion, and jacket expansion, respectively. Dimensionally, each of the feedback amplitudes is defined by the following:

$$
A_{i}=P X_{i}=P(\Delta k / k / \triangle P)_{i},
$$

where $P$ is the reactor power and $(\Delta k / k / \Delta P)_{i}$ is the power coefficient of reactivity for the $\mathrm{i}^{\text {th }}$ process. In this and subsequent discussions, the reactor power will be given in kilowatts, and the power coefficient will be given in inhours or reactivity units per kilowatt. By definition of the feedback $H$ [see Eq. (15)], the sign of $X_{i}$ is negative when the power coefficient is positive. Conversely, its sign is positive when the power coefficient is negative. Whether the net prompt feedback effect is positive or negative depends on the magnitude and sign of each term of Eq. (17).

Since axial fuel expansion and slug bowing operate on a very similar time base, their effects are described by the first term on the right-hand side of Eq. (17) where $A_{f}$ is the algebraic sum of the respective components and $\tau_{f}$ is the time constant for fuel-deformation effects. Specifically, $\tau_{f}$ is the time required, following a power perturbation, for the resultant reactivity change to reach $63.2 \%$ of its final value.

Similarly, the prompt effects from jacket heating (radial expansion and bowing) are described by the third term on the right-hand side of Eq. (17) which includes a common time constant, $\tau_{j}$, and a common feedback reactivity, $A_{j}$, which is the algebraic sum of the negative and positive components. The second term describes the expulsion of $\mathrm{NaK}$ from the annulus following a power change. In this case, a single negative component is involved. 
4. Mathematical Reduction of the Prompt Term

As a first step in the simplification process, the denominators of the terms in Eq. (17) may be expanded:

$$
\begin{aligned}
H= & \frac{A_{f}}{1+i \omega \tau_{f}}+\frac{A_{a}}{1-\omega^{2} \tau_{f} \tau_{a}+i \omega\left(\tau_{f}+\tau_{a}\right)} \\
& +\frac{A_{j}}{1+i \omega\left(\tau_{f}+\tau_{a}+\tau_{j}\right)-\omega^{2} \tau_{f} \tau_{a}-\omega^{2} \tau_{j}\left(\tau_{f}+\tau_{a}\right)-i \omega^{3} \tau_{f} \tau_{a} \tau_{j}}
\end{aligned}
$$

According to Mohr, (24) who has evaluated time constants of the fuel and cladding of Mark IV for typical full-power operating conditions, $\tau_{f}$ is of the order of $0.5 \mathrm{sec}, \tau_{\mathrm{a}}<0.1 \mathrm{sec}$, and $\tau_{j}$ is of the order of $0.1 \mathrm{sec}$. Accordingly, it is permissible, as a first approximation, to drop all terms containing cross products which involve either $\tau_{a}$ or $\tau_{j}$. The approximation is particularly applicable at low frequencies for which $\omega^{2}$ and $\omega^{3}$ are insignificantly small. Hence Eq. (19) becomes

$$
H=\frac{A_{f}}{1+i \omega \tau_{f}}+\frac{A_{a}}{1+i \omega\left(\tau_{f}+\tau_{a}\right)}+\frac{A_{j}}{1+i \omega\left(\tau_{f}+\tau_{a}+\tau_{j}\right)} .
$$

A final assumption is made that the time dependence of the first term on the right-hand side of Eq. (16) may be approximated by a single time constant, $\tau_{1}=\tau_{f}+\tau_{a}+\tau_{j}$. Essentially, then, $\tau_{1}$ is an effective time constant for all prompt feedback processes and is only slightly larger than the time constant for fuel expansion. As discussed in Section IV, the assumptions necessary to reduce Eq. (17) to a single feedback term, although acceptably valid at lower frequencies, compromises the quality of a synthetic fit at the higher frequencies. As a result of the various simplifications, the first term on the right-hand side of Eq. (16) may be written in the form

$$
\mathrm{H}(\mathrm{prompt})=\mathrm{A}_{0} /\left(1+i \omega \tau_{1}\right)
$$

where $A_{0}$ is the algebraic sum of all prompt reactivity-feedback effects which act along a time base dictated by the common time constant $\tau_{1}$.

\section{Mathematical Description of the Delayed Term}

As discussed in Section IV-B-2, the delayed term of Eq. (16) considers delayed reactivity-feedback effects from NaK expulsion, the radial expansion and bowing of jackets, and the expansion of stainless steel hexes. If simplifying assumptions such as those discussed in Section IV-B-4 are made, the effective feedback from all delayed effects is given by

$$
\mathrm{H}(\text { delayed })=B_{0} /\left(1+i \omega \tau_{1}\right)\left(1+i \omega \tau_{2}\right)
$$


where $B_{0}$ is the algebraic sum of all zero-frequency delayed feedback effects, and $\tau_{2}$ is a time constant shared in common by the various delayed components. The total feedback sensed by the system is simply the sum of Eqs. (21) and (22); hence,

$$
\begin{aligned}
& H(\text { total })=\frac{A_{0}}{1+i \omega \tau_{1}}+\frac{B_{0}}{\left(1+i \omega \tau_{1}\right)\left(1+i \omega \tau_{2}\right)} \\
& \text { 6. The Significance of the Simplified Model }
\end{aligned}
$$

In essence, Eq. (23) is the mathematical result of lumping all prompt and all delayed feedback effects into two separate terms, both of which, when properly evaluated, lead to important conclusions regarding the stability of the system. Although both terms have been considerably simplified, it is still clear from Eq. (23) that at low frequencies the gain constant $A_{0}$ in $E q$. (21) gives an acceptably accurate estimate for prompt feedback effects. Although not as obvious, but true within the same limitations, the magnitude of the gain constant $B_{0}$ reflects the importance of delayed radial feedback effects. The phasing of the two terms, relative to the sinusoidal forcing function and to each other, is dictated by the two time constants $\tau_{1}$ and $\tau_{2}$. An evaluation of these important parameters permits considerable insight into the various feedback processes which affect the overall stability of the system.

C. Evaluation of $A_{0}, B_{0}, \tau_{1}$, and $\tau_{2}$

The method used to establish values for $A_{0}, B_{0}, \tau_{1}$, and $\tau_{2}$ is based on a successive approximation of individual parameters followed by a "cut and try" shaping of the best-fit values. The real and imaginary components of $\mathrm{H}$ as given in Eq. (23) are

$$
\begin{aligned}
& \{\mathrm{H}\}_{\mathrm{Re}}=-\frac{\mathrm{A}_{0}}{1+\omega^{2} \tau_{1}^{2}}+\frac{\mathrm{B}_{0}\left(1-\omega^{2} \tau_{1} \tau_{2}\right)}{\left(1+\omega^{2} \tau_{1}^{2}\right)\left(1+\omega^{2} \tau_{2}^{2}\right)} \\
& \{\mathrm{H}\}_{\mathrm{Im}}=\frac{\mathrm{A}_{0} \omega \tau_{1}}{1+\omega^{2} \tau_{1}^{2}}-\frac{\mathrm{B}_{0} \omega\left(\tau_{1}+\tau_{2}\right)}{\left(1+\omega^{2} \tau_{1}^{2}\right)\left(1+\omega^{2} \tau_{2}^{2}\right)} .
\end{aligned}
$$

The logical supposition is that $\tau_{2}>\tau_{1}$. It is then clear from Eq. (25) that for low frequencies the imaginary component of the prompt term is small, while the real component is close to its maximum value of $A_{0}$. It is also clear that attenuation effects dictated by $\omega^{2} \tau_{1}^{2}$ are small. Accordingly, all $\omega^{2} \tau_{1}^{2}$ terms may be dropped from Eqs. (24) and (25) with little loss of significance:

$$
\{\mathrm{H}\}_{\mathrm{Re}}=\mathrm{A}_{0}+\frac{\mathrm{B}_{0}\left(1-\omega^{2} \tau_{1} \tau_{2}\right)}{1+\omega^{2} \tau_{2}^{2}}
$$




$$
\{\mathrm{H}\}_{\mathrm{Im}}=-\mathrm{A}_{0} \omega \tau_{1}-\frac{\mathrm{B}_{0} \omega\left(\tau_{1}+\tau_{2}\right)}{1+\omega^{2} \tau_{2}^{2}} .
$$

With four unknown parameters, $A_{0}, B_{0}, \tau_{1}$, and $\tau_{2}$, and two equations, some further simplification is necessary. Obviously, as $\omega$ approaches zero, the imaginary component, approximated by Eq. (27), vanishes and the real component approaches the sum of $A_{0}$ and $B_{0}$. From a plot of the feedback amplitude as a function of frequency, it is possible to establish a value for the sum $A_{0}+B_{0}$ by means of an extrapolation to zero frequency. It is also possible, from a Bode $(25)$ analysis of the feedback, to estimate a value for the longer time constant, $\tau_{2}$. With the use of experimental values for the real and imaginary components, and of estimated values for $\tau_{2}$ and the sum $A_{0}+B_{0}$, Eqs. (26) and (27) may be solved simultaneously at low fre quencies for $\tau_{1}, \tau_{2}, A_{0}$, and $B_{0}$. Since Eqs. (26) and (27) are quadratic in $\tau_{2}$, care must be taken to discard trivial solutions. Having established an estimate for $\tau_{1}$, Eqs. (24) and (25) can be solved for better values of $A_{0}$ and $B_{0}$, this time with the $\omega^{2} \tau_{1}^{2}$ terms included. Repetition of this procedure for additional low-frequency data points, followed by a parametric shaping with an IBM-1620 computer, leads eventually to a set of values for $A_{0}, B_{0}, \tau_{1}$, and $\tau_{2}$ which best describe the feedback behavior over the entire frequency range.

The results of parametric fitting for the various data sets are given in Table VII. Comparisons between experimental and calculated results are given graphically in Figs. 10 through 14. For frequencies up to about $0.15 \mathrm{cycle} / \mathrm{sec}$, the agreement between experimental and calculated results is fair, considering the approximate method used for evaluating the various parameters. At higher frequencies, the less satisfactory agreement is most likely the result of a combination of factors, among them the inaccuracies originating from the feedback separation. (The problem of separating a feedback function at high frequencies is essentially one of measuring a small difference between two large numbers of comparable magnitude. The effects of errors intrinsic in either or both are amplified when a difference is taken.)

Table VII

SUMMARY OF BEST-FIT PARAMETRIC DATA

\begin{tabular}{|c|c|c|c|c|c|c|}
\hline $\begin{array}{c}\text { Power, } \\
\text { kW }\end{array}$ & $\begin{array}{c}\text { Flow Rate, } \\
\text { gpm }\end{array}$ & $\begin{array}{c}\text { Inlet Temp, } \\
{ }^{\circ} \mathrm{C}\end{array}$ & $\begin{array}{c}\mathrm{A}_{0} \\
(\Delta \mathrm{k} / \mathrm{k}) \times 10^{3}\end{array}$ & $\begin{array}{c}\mathrm{B}_{0} \\
(\Delta \mathrm{k} / \mathrm{k}) \times 10^{3}\end{array}$ & $\begin{array}{l}\tau_{1} \\
\text { sec }\end{array}$ & $\begin{array}{l}\tau_{2} \\
\text { sec }\end{array}$ \\
\hline 510 & 265 & 50 & 0.00 & 0.515 & 0.40 & 1.78 \\
\hline 878 & 281 & 51 & 0.05 & 1.00 & 0.50 & 1.37 \\
\hline 1193 & 286 & 73 & 0.10 & 1.55 & 0.50 & 1.41 \\
\hline 1120 & 291 & 173 & 0.00 & 2.30 & 0.35 & 2.15 \\
\hline 930 & 294 & 230 & -0.10 & 2.10 & 0.40 & 2.30 \\
\hline
\end{tabular}




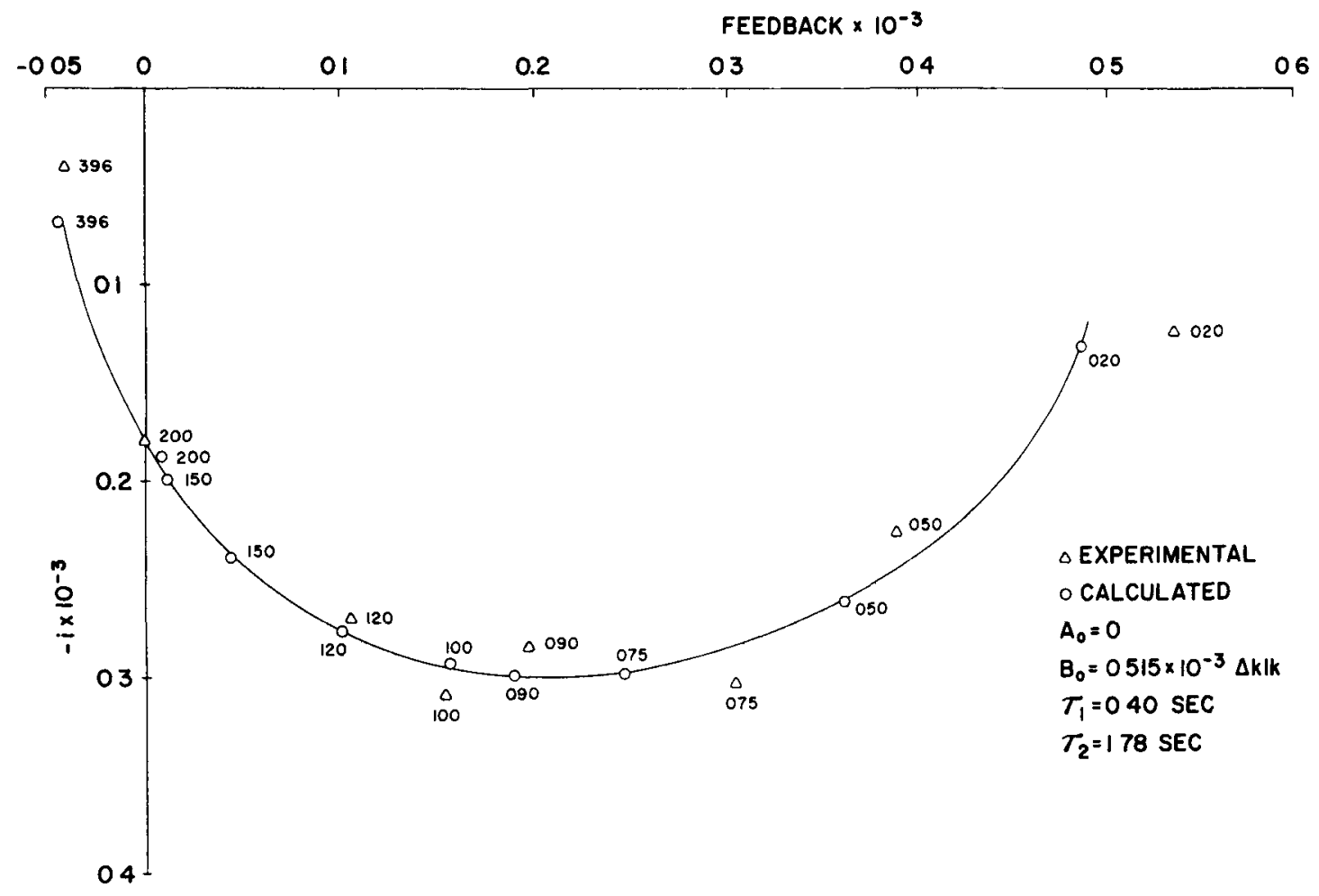

Fig. 10. Comparison of Experimental and Calculated Feedbacks for $510 \mathrm{~kW}, 265 \mathrm{gpm}$, and $50^{\circ} \mathrm{C}$

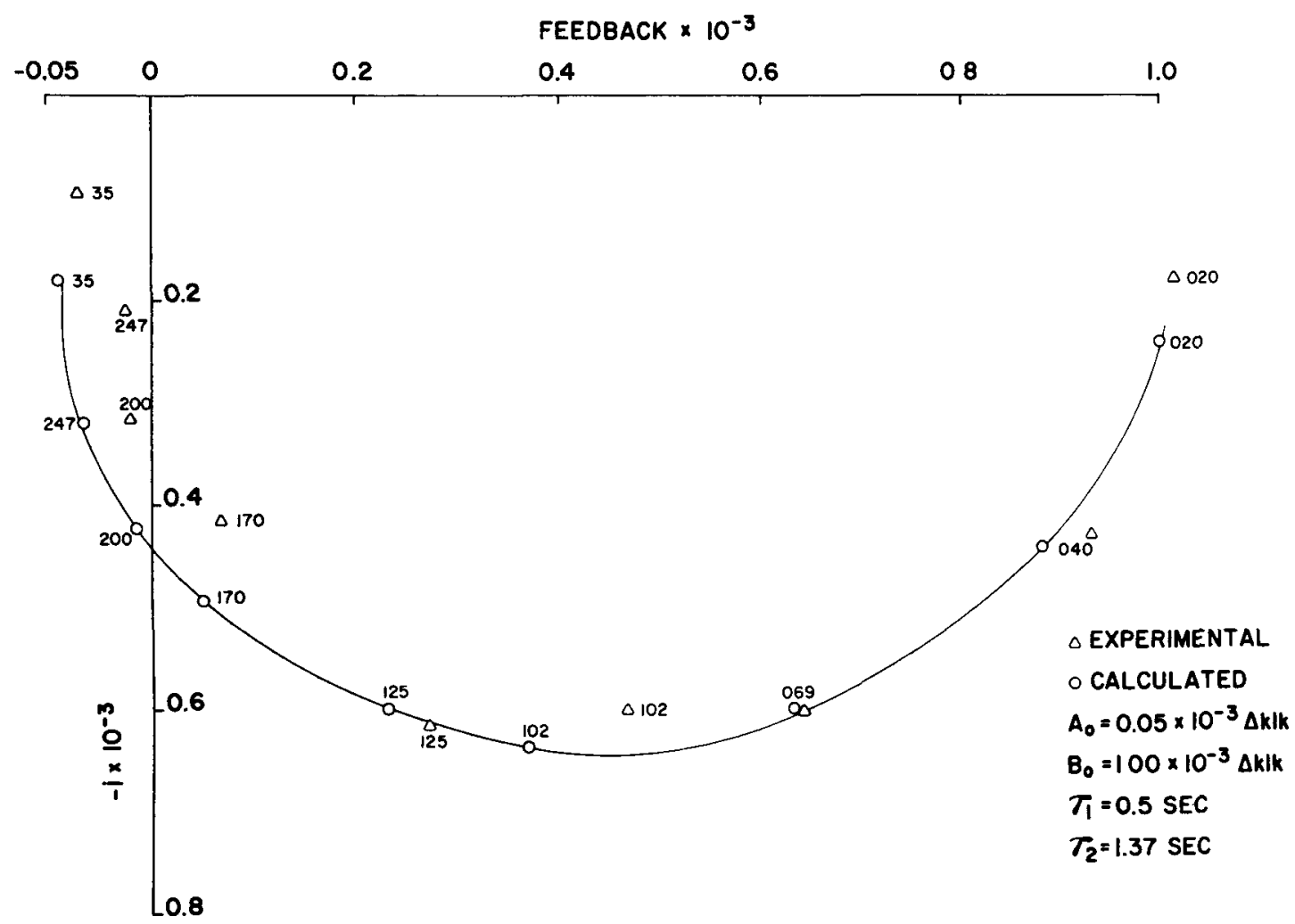

Fig. 11. Comparison of Experimental and Calculated Feedbacks for $878 \mathrm{~kW}, 28 \mathrm{gpm}$, and $51^{\circ} \mathrm{C}$ 


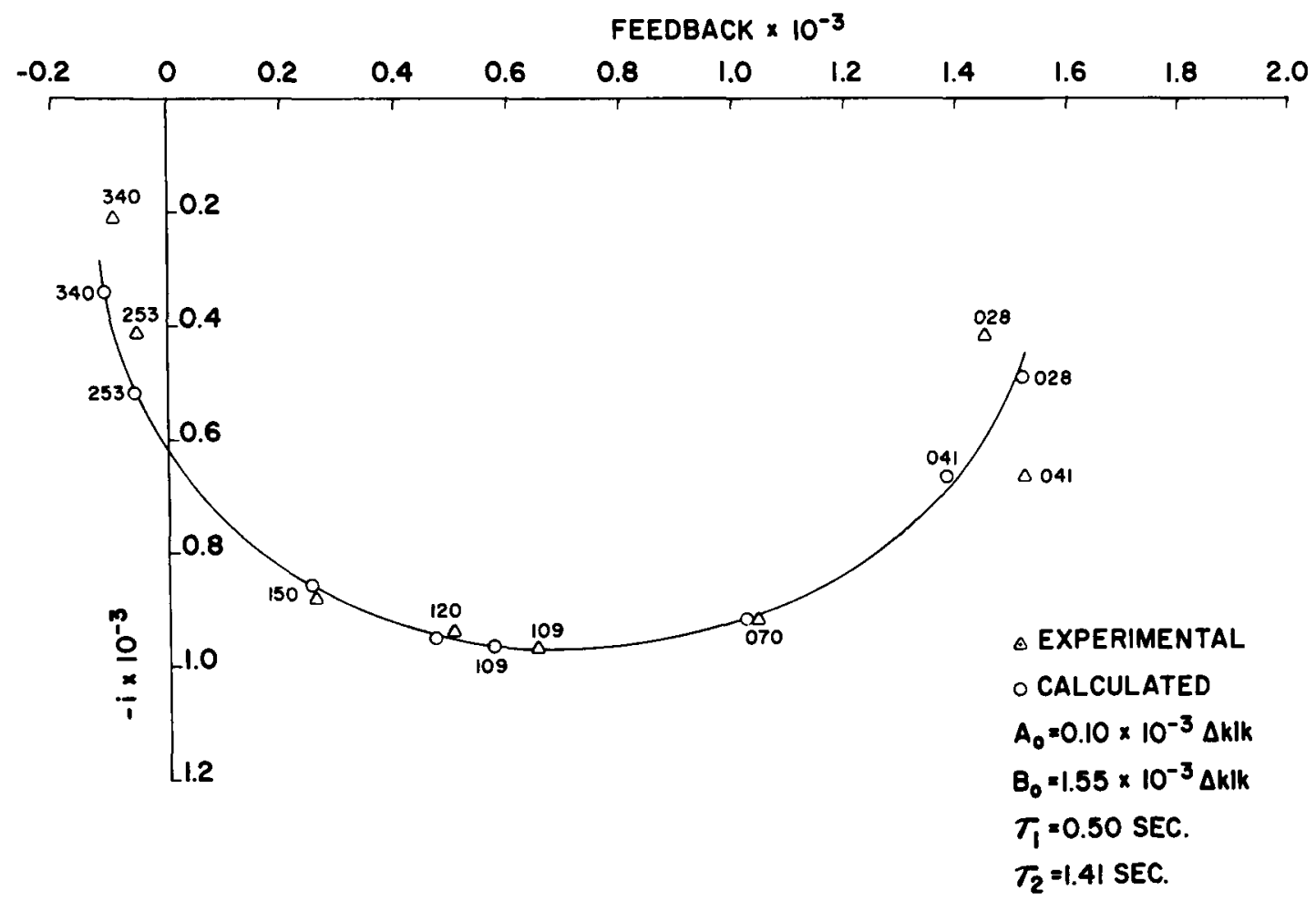

Fig. 12. Comparison of Experimental and Calculated Feedbacks for $1193 \mathrm{~kW}, 286 \mathrm{gpm}$, and $73^{\circ} \mathrm{C}$

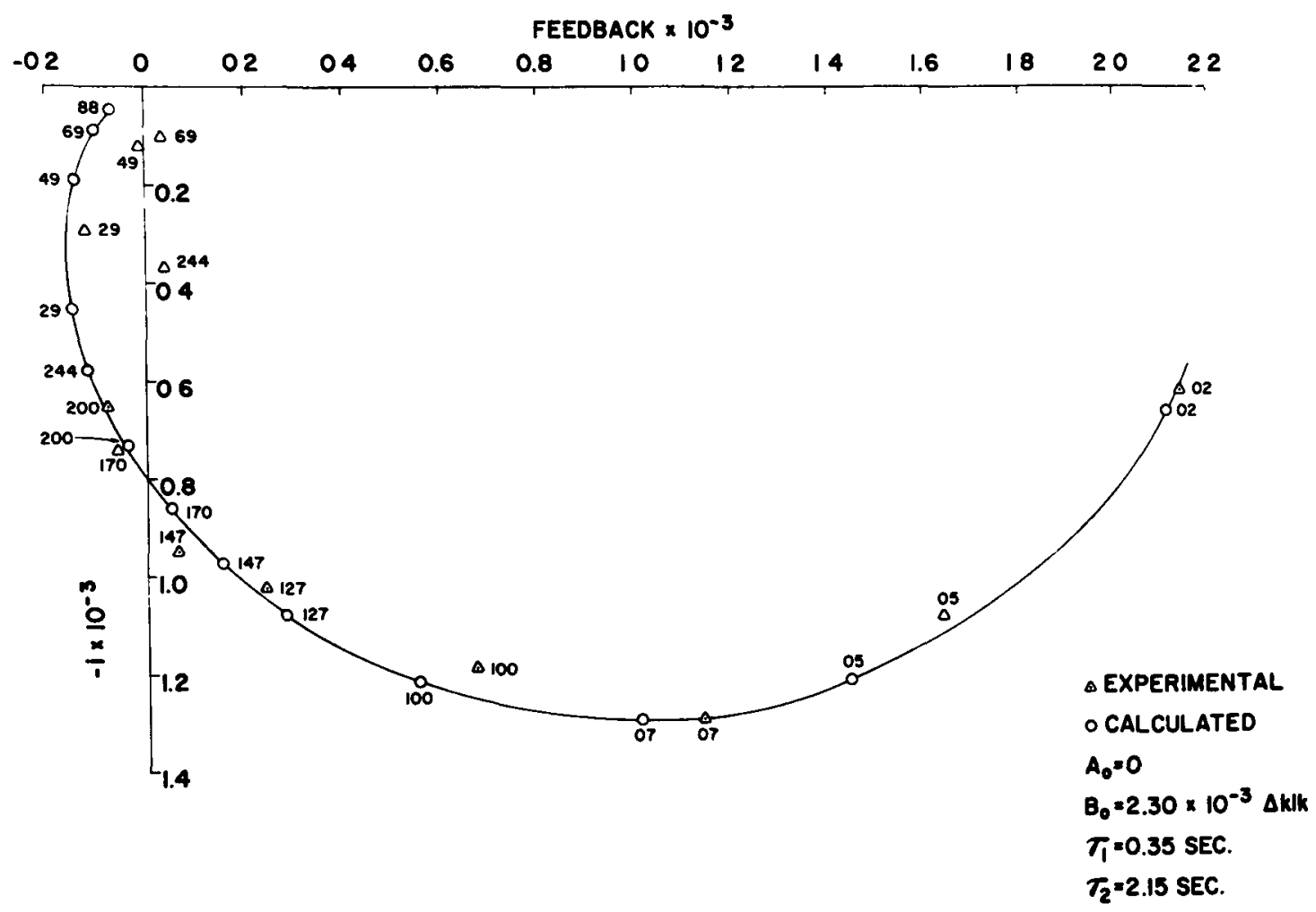

Fig. 13. Comparison of Experimental and Calculated Feedbacks for $1120 \mathrm{~kW}, 291 \mathrm{gpm}$, and $175^{\circ} \mathrm{C}$ 


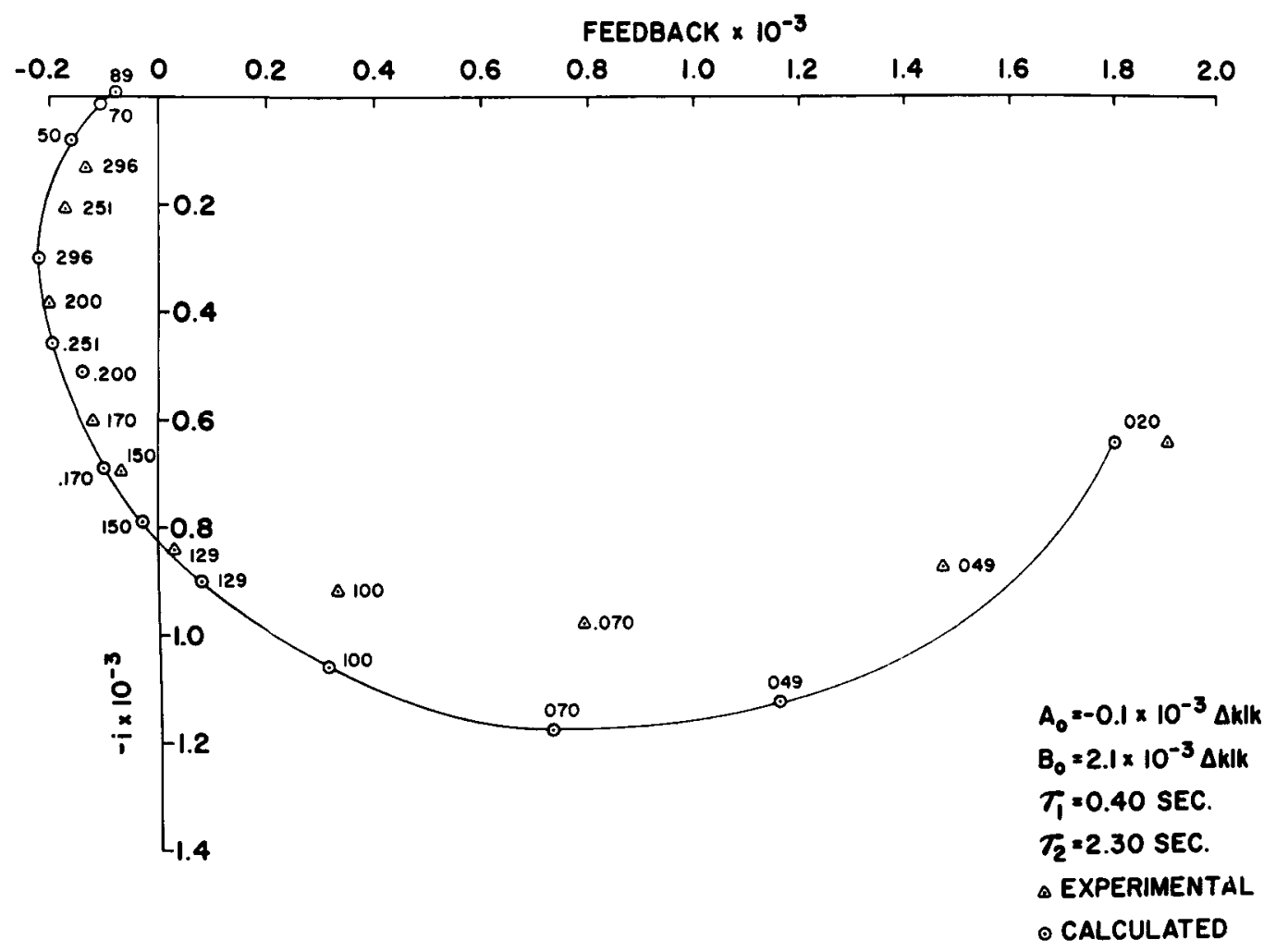

Fig. 14. Comparison of Experimental and Calculated Feedbacks for $930 \mathrm{~kW}, 294 \mathrm{gpm}$, and $230^{\circ} \mathrm{C}$

Also contributing to the apparent discrepancy are the effects of simplifying the exact model by lumping, and the failure to establish more satisfactory empirical values for $A_{0}, B_{0}, \tau_{1}$, and $\tau_{2}$. With little doubt, additional effort would lead to a better agreement between experimentallymeasured and calculated feedback data points. The change in parametric values listed in Table VII, however, would be small and would in no way influence general conclusions resulting from the study.

D. Significance of Parametric Values

An inspection of the parametric data summarized in Table VII reveals that values for the effective fuel time constant range from 0.35 to $0.50 \mathrm{sec}$. Each of these is in reasonable agreement with the value of 0.50 sec calculated by Mohr(24) for EBR-I Mark-IV fuel at full power, full flow, and for a low $\left(70^{\circ} \mathrm{C}\right)$ inlet temperature. The tendency for the individual values to be lower at higher temperatures reflects the increased specific conductivity of the fuel material.

The values established for the time constant of the delayed term, although varying from 1.37 to $2.30 \mathrm{sec}$, are qualitatively consistent with the concept of a transport lag which, for simplicity, has been considered as a simple time constant in the denominator of Eqs. (22) and (23). 
A further inspection of the parametric data given in Table VII results in the rather surprising conclusion that in all cases the power coefficient for the radial (delayed) term exceeds by a very wide margin the power coefficient for the respective axial (prompt) component. In fact, for one data set, that at $930 \mathrm{~kW}, 294 \mathrm{gpm}$, and $230^{\circ} \mathrm{C}$, the power coefficient for the axial term is positive.

To appreciate the significance of these conclusions, it is instructive to consider the special situation in which the temperature of all components in the core and inner blanket are increased by the same amount. The associated reactivity change is given by

$$
\frac{\Delta \mathrm{k}}{\mathrm{k}}=-\mathrm{C} \frac{\Delta \mathrm{V}}{\mathrm{V}} \text {, }
$$

where $\mathrm{C}$ is a constant and $\Delta \mathrm{V} / \mathrm{V}$ is the fractional change in core volume resulting from thermal expansion of the various components. In cylindrical geometry, the volume of the system is given by

$$
V=\pi r^{2} h .
$$

Taking partial derivatives

$$
\begin{aligned}
& \left(\frac{\partial V}{\partial r}\right)_{h}=2 \pi r h ; \\
& \left(\frac{\partial V}{\partial h}\right)_{r}=\pi r^{2} .
\end{aligned}
$$

The volume change associated with some arbitrary increase of temperature may be approximated by

$$
\Delta V=\left(\frac{\partial V}{\partial r}\right)_{h} \Delta r+\left(\frac{\partial V}{\partial h}\right)_{r} \Delta h
$$

Substitution of Eqs. (30) and (31) into (32) gives

$$
\Delta \mathrm{V}=2 \pi \mathrm{rh} \Delta \mathrm{r}+\pi \mathrm{r}^{2} \mathrm{~h} \Delta \mathrm{h} \text {. }
$$

Finally, division of Eq. (33) by Eq. (29) results in

$$
\frac{\Delta \mathrm{k}}{\mathrm{k}}=-\mathrm{C}\left(2 \frac{\Delta \mathrm{r}}{\mathrm{r}}+\frac{\Delta \mathrm{h}}{\mathrm{h}}\right) \text {, }
$$

where $\Delta \mathrm{r} / \mathrm{r}$ and $\Delta \mathrm{h} / \mathrm{h}$ are the fractional changes in core radius and height, respectively. For the situation in which linear expansion coefficients are 
the same, both radially and axially, and for a uniform temperature change, it follows from Eq. (34) that radial expansion is twice as effective as axial expansion in changing reactivity.

For Mark IV, the radial component of expansion is dictated by the linear expansion coefficient of Zircaloy-2 $\left(9.6 \times 10^{-6} \mathrm{\Delta L} / \mathrm{L} /{ }^{\circ} \mathrm{C}\right)$, whereas the axial component is dictated by the linear expansion coefficient of the fuel $\left(12.5 \times 10^{-6} \Delta \mathrm{L} / \mathrm{L} /{ }^{\circ} \mathrm{C}\right)$. For a uniform temperature increase there will be a preferential axial expansion. Accordingly, an additional weight must be placed on the axial component. Furthermore, for a power increase, temperature changes in the fuel are substantially larger than those occurring in the cladding. It follows that a given power increase will result in a disproportionate increase in the axial dimension of the core. Again, an additional weight must be placed on the importance of the axial expansion component. The actual relative weights to be placed on the two components have not been established, but it is reasonable to assume that the two terms should, at the very least, be of comparable magnitude. It is surprising then to discover experimentally that the axial component is extremely weak and under certain conditions changes sign.

E. Slug Bowing

The most likely explanation of this discrepancy concerns the possibility of fuel slug bowing. Because of flux-bending across the core, the temperature of the fuel slug surface facing the high-flux center will be higher than the temperature associated with the opposite surface. The inner surface tends to expand relative to the outer surface, with the result that the slug bows in the direction of the higher flux. Such an effect tends to move fuel towards the vertical axis of symmetry and is, of course, positive.

An additional positive component originates from the bowing of jackets. Since coolant temperatures are higher in inner channels, a temperature differential exists between inner and outer jacket surfaces. Such an effect is manifested by the bowing of jackets which again tends to move fuel towards the center of the core. Logically, the importance of jacketbowing effects depends on the freedom of fuel rods to move in a radial direction. As discussed in more detail below (Section IV-G) the degree of permissible radial movement depends on a temperature-sensitive system of clearances.

There is, of course, a negative component from axial fuel expansion, but whether the net power coefficient is positive or negative depends on a variety of factors, among them the power and coolant flow rate. The size and shape of the individual fuel slugs and the existence of spacer ribs along the jackets must also be taken into consideration. 
An illustration of an important feature, fundamental to future discussions, is given in Fig. 15. Shown in exaggerated form are four longi-

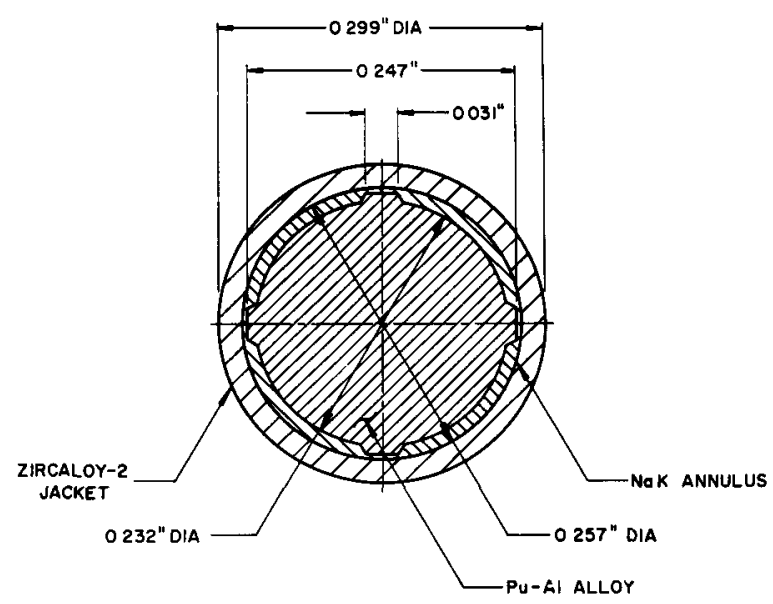

Fig. 15. Cross Section through Mark-IV Fuel Rod tudinal ribs rolled into the surface of fuel slugs during fabrication. The ribs were incorporated primarily for the purpose of centering the slugs concentrically in the jackets. Under idealized conditions the radial separation distance between ribs and jacket amounts to 5 mils. It follows that even small distortions can affect contact between ribs and jackets.

The concept of radial clearance is illustrated in Fig. 16. For simplicity fuel slug ribs have been omitted and the radial clearances illustrated are those existing between ribs and jackets. Blanket slugs are concentrically positioned by a system of upper and lower "stakes" formed during fabrication operations. In Fig. 16 the radial scale of dimensions has been greatly exaggerated for illustrative purposes. At zero power (see Fig. 16a) each slug is shown in a position symmetric with respect to the vertical axis.

As the power level of the reactor increases, fuel slugs (and to a lesser extent, blanket slugs) begin to assume a bow-like configuration. Figure 16b illustrates the case for an unsaturated degree of bowing, i.e., one in which bowing is insufficient to effect contact between the arc of the bow and the inner surface of the jacket. This situation is more or less typical of fuel slugs located either in a gentle flux gradient at full power or in a strong gradient at low power. Note that the degree of bowing for the uppermost fuel slug
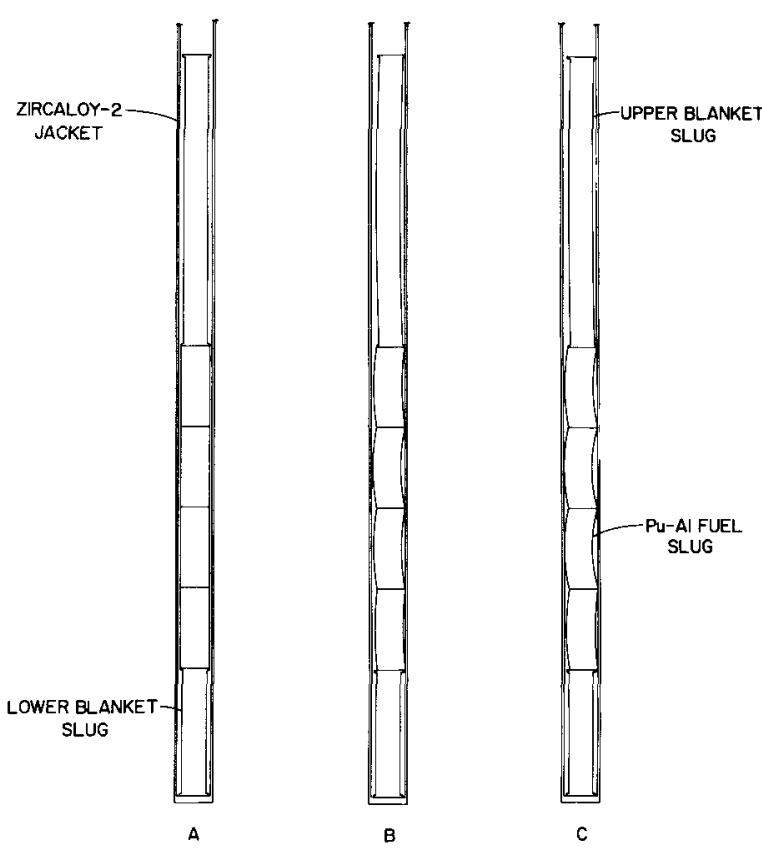

Fig. 16. Fuel Slug Bowing is greater than for its lowermost counterpart. A greater degree of bowing for the uppermost slug is the consequence of a higher temperature differential between coolant channels at higher elevations.

Additional increases in power increase the degree of bowing to the extent that the arc of the bow may eventually contact the inner surface of 
the jacket. Under these conditions, the bowing becomes saturated, i.e., additional increases in power effect little, if any, additional reactivity increases. An illustration of this effect is given in Fig. 16c. Obviously, for any given rod, one or both central fuel slugs may be characterized by saturation while the remaining fuel slugs may still be unsaturated.

The extent to which the prompt coefficient is affected by slug bowing is apparently governed by a competition between two major reactivity effects, both of which must be integrated over the entire volume of the core. For the central region in which the flux gradient is small, the degree of saturation will be relatively small. The effects of power increases will be manifested primarily by axial expansion, and the associated power coefficient component will most likely be negative. A limited amount of slug bowing will occur with the result that a portion of the negative axial expansion component will be cancelled.

For the region intermediate between the central hex and the edge of the core, and characterized by a very definite flux gradient, a strong competition between slug bowing and axial expansion exists. Which effect predominates depends on the degree of saturation, which in turn depends on the power, coolant flow rate, coolant inlet temperature, and the exact radial position of the fuel rod. Strong slug-bowing effects should be characteristic of this region.

Finally, for fuel rods located along the periphery of the core, where the flux gradient is extremely steep, it seems likely that the degree of saturation will be high. Under these conditions, the axial expansion effect will predominate and the associated power coefficient component for this region will be negative.

Clearly, the net effect integrated over the entire system is not easily susceptible to mathematical treatment since the associated power coefficient is dependent on the overall degree of saturation, which in turn is very likely a complicated statistically regulated variable.

F. Additional Slug-bowing Evidence

The following items of experimental information are consistent with the concept of a strong slug-bowing power coefficient component.

\section{Power Coefficient Measurements}

Fundamental to this discussion is the concept that after a fuel slug bows to saturation, additional power increases effect little if any changes in geometric distortion. For these special conditions it seems likely that the reactivity change associated with a power increase will be negative, since axial expansion will still be possible, at least to a limited 
extent. If, however, the force of bowing is sufficient to deform the jackets and allow fuel to move towards the center of high flux, the positive bowing component will not necessarily vanish upon saturation. In view of the system of ribs and tightening rods incorporated into the design of Mark IV, the freedom of jackets to bend and to move inward under the influence of slug bowing is very likely limited. Such effects, if existent, will also tend to saturate after closure of small clearances between fuel rods. In subsequent discussions, no attempt will be made to distinguish between the two saturation effects since both act in the same direction and along essentially the same time base.

If reasonable skepticism is exercised, useful information may result from static measurements of the power coefficient. In the usual determination of power coefficient, a known amount of reactivity is withdrawn. Since the steady-state power coefficient in Mark IV is known to be negative, the power decreases and eventually levels off at a lower asymptotic limit. Division of the reactivity withdrawn by the change in power yields directly the power coefficient of reactivity. Usually, the total reactivity withdrawn is plotted as a function of power and the slope of the best-fit straight line through the individual data points is interpreted directly in terms of the power coefficient of reactivity. Alternatively, the total reactivity withdrawn may be divided by the total power change. Both methods amount, essentially, to averaging a collection of individual data points.

The results of three series of power coefficient measurements are summarized in Table VIII. In all cases, the reactivity withdrawn or inserted, as the case may be, corresponds to the full worth ( $30.5 \mathrm{Ih})$ of a

Table VIII

POWER COEFFICIENT MEASUREMENTS FOR EBR-I, MARK IV

\begin{tabular}{|c|c|c|c|c|}
\hline $\begin{array}{c}\text { Initial Power, } \\
\text { kW }\end{array}$ & $\begin{array}{c}\text { Final Power, } \\
k W\end{array}$ & $\begin{array}{c}\text { Reactivity Change, } \\
\text { Ih }\end{array}$ & $\begin{array}{c}\text { Power Change, } \\
\mathrm{kW}\end{array}$ & $\begin{array}{c}\Delta \mathrm{k} / \mathrm{k} / \Delta \mathrm{P} \\
\mathrm{Ih} / \mathrm{kW}\end{array}$ \\
\hline \multicolumn{5}{|c|}{ Decreasing Power, Inlet Temperature of $66^{\circ} \mathrm{C}$} \\
\hline 1134 & 978 & 275 & 156 & 0176 \\
\hline 978 & 802 & 236 & 176 & 0134 \\
\hline 802 & 478 & 512 & 324 & 0158 \\
\hline 478 & 325 & 293 & 153 & 0192 \\
\hline 325 & 207 & 269 & 118 & 0228 \\
\hline \multicolumn{5}{|c|}{ Increasing Power, Inlet Temperature of $68^{\circ} \mathrm{C}$} \\
\hline 195 & 381 & 326 & 186 & 0175 \\
\hline 381 & 485 & 269 & 103 & 0261 \\
\hline 485 & 605 & 235 & 120 & 0196 \\
\hline 605 & 713 & 218 & 108 & 0202 \\
\hline 713 & 852 & 302 & 139 & 0217 \\
\hline 852 & 1088 & 422 & 236 & 0179 \\
\hline \multicolumn{5}{|c|}{ Decreasing Power, Inlet Temperature of $200^{\circ} \mathrm{C}$} \\
\hline 1028 & 866 & 299 & 162 & 0185 \\
\hline 866 & 693 & 270 & 173 & 0156 \\
\hline 693 & 536 & 293 & 157 & $\begin{array}{lll}0 & 187\end{array}$ \\
\hline 536 & 341 & 365 & 195 & $\begin{array}{ll}0 & 187\end{array}$ \\
\hline
\end{tabular}


safety or control rod. The effects of drifts in inlet temperature which occur during the measurements have been considered by applying a correction of $3.0 \mathrm{Ih} /{ }^{\circ} \mathrm{C}$ to the reactivity change. The frequent necessity for such corrections is reflected directly by the widely differing values appearing in column 3. Division of the reactivity change, given in column 3 , by the power decrease (or increase) gives the power coefficient listed under column 5. Values averaged over a wide range of power, for different inlet temperatures and for different modes of power changes, are summarized in Table IX.

Table IX

AVERAGE POWER COEFFICIENT VALUES

\begin{tabular}{|c|c|c|c|c|}
\hline $\begin{array}{l}\text { Mode of } \\
\text { Power } \\
\text { Change }\end{array}$ & $\begin{array}{l}\text { Power } \\
\text { Range, } \\
\mathrm{kW}\end{array}$ & $\begin{array}{l}\text { Inlet } \\
\text { Temp, } \\
{ }^{\circ} \mathrm{C}\end{array}$ & $\begin{array}{c}\text { Average Power } \\
\text { Coefficient, } \\
\text { Ih } / \mathrm{kW}\end{array}$ & $\begin{array}{l}\text { Average Power } \\
\text { Coefficient, } \\
\Delta \mathrm{k} / \mathrm{k} / \mathrm{kW} \times 10^{6}\end{array}$ \\
\hline Decreasing & $1134-478$ & 66 & 0.156 & 1.64 \\
\hline Increasing & $381-1088$ & 68 & 0.205 & 2.16 \\
\hline Decreasing & $1028-341$ & 206 & 0.179 & 1.88 \\
\hline
\end{tabular}

Although not immediately apparent, the data summarized in Tables VIII and IX are completely consistent with the concept of slug bowing. To appreciate this important conclusion, it is instructive to consider the sequential mechanical effects resulting from a continual (interrupted) power increase over a wide range. Although the following arguments apply primarily for fuel rods located in the outer ring of six hexes, they also apply with less emphasis for the fuel rods located within the central subassembly.

As the reactor power increases, individual slugs begin to bow. Since they also expand longitudinally, the axial power coefficient is the algebraic sum of the individual effects. At low power $(0-400 \mathrm{~kW})$ few if any of the fuel slugs will be bowed to saturation, with the result that the power coefficient will be weak. While perhaps fortuitous, the data of Table VIII indicate that over the power range $195-381 \mathrm{~kW}$, the measured power coefficient is indeed smaller than that for the range from $381 \mathrm{~kW}$ to essentially full power.

Because of mechanical imperfections and location within the core, a tendency exists for each fuel slug to saturate at some characteristic power. The process is, of course, statistically gradual: more and more slugs tend to saturate as the power increases. If the forces of axial expansion are assumed to be sufficient to overcome contact frictional effects (from saturated slugs), the column of slugs at full power will be uninterrupted, i.e., gaps between individual fuel slugs will not exist. Under these conditions, individual axial expansion effects will combine through an end-to-end contact and will result in a maximum value for the power coefficient. 
If, however, the power coefficient is measured as the power decreases, fuel slugs bowed to saturation will remain in position until the power drops below the saturation value. Under these conditions, gaps will exist between all saturated slugs and between the lowermost saturated slug and its lower neighbor. The full extent of contraction will not be reached until the power level falls below the lowest saturation value. When this happens, the entire column above the last saturated slug falls. Logically, then, the power coefficient should be weak at high power and become very much stronger as the saturated slugs are released at low power. That such is indeed the case is apparent from an inspection of the data given in Table VIII for decreasing power at an inlet temperature of $66^{\circ} \mathrm{C}$. From 1134 to $478 \mathrm{~kW}$, the average power coefficient amounts to $0.156 \mathrm{Ih} / \mathrm{kW}$. From 478 to $207 \mathrm{~kW}$, the average values increase to $0.207 \mathrm{Ih} / \mathrm{kW}$. In contrast, the power coefficient for the case of increasing power is weak at low power $(0.175 \mathrm{Ih} / \mathrm{kW}$ from 195 to $381 \mathrm{~kW})$ and very strong at high power (an average of $0.205 \mathrm{Ih} / \mathrm{kW}$ from 381 to $1088 \mathrm{~kW}$ ). Such behavior strongly supports the validity of the slug-bowing concept.

\section{Irregularities in the Power Coefficient}

Power coefficient measurements in Mark III(11) (in which the fuel and cladding were coextruded) were usually characterized by reproducibility and by a high degree of linearity. A plot of total reactivity withdrawn as a function of power was usually described as a series of points lying on or close to a straight line. A similar plot of Mark-IV data, on the other hand, is characterized by a significantly greater degree of scatter in the data points. Evidence of this behavior is given by the information of Table VIII. Thus, for decreasing power (at inlet temperature of $66^{\circ} \mathrm{C}$ ) differential values of the power coefficient range from a low of 0.131 to a high of $0.228 \mathrm{Ih} / \mathrm{kW}$, a factor of almost two. Such differences suggest a discontinuous process, such as the sudden release of saturated slugs at some critical value of power. Since power changes involved for a single data point amount to as much as $200 \mathrm{~kW}$, the release of a large number of slugs is possible.

From the evidence cited in Sections IV-B through IV-F, it seems clear that the negative power coefficient component from axial fuel expansion is almost completely cancelled by positive effects also originating in the fuel. In view of the evidence cited above, it seems reasonable to identify the positive effect with the inward bowing of fuel slugs during a power increase.

\section{G. Effect of Inlet Temperature on Feedback}

From an inspection of the data given in Fig. 9, it is clear that variations in the inlet temperature cause strong changes in the amplitude of the feedback. Unfortunately, it is difficult to assess the true magnitude of the 
inlet temperature effect from the data of Fig. 9, since each data set was obtained under different conditions of power and flow. To obtain a more realistic estimate of the inlet temperature effect, it is instructive to nor malize the data from two sets to that of a third. If as a first approximation it is assumed that the feedback varies directly as the power and inversely as the flow rate, the data sets for 1120 and $930 \mathrm{~kW}$ were normalized to the data set at $1193 \mathrm{~kW}$. Neither assumption is seriously compromising since the differences in flow rates between sets are small, and the power coefficients of reactivity in the region of interest are to a first approximation linear.

The results of the normalization are given in Fig. 17. Of particular interest is the fact that increasing the inlet temperature from 73 to $175^{\circ} \mathrm{C}$ results in an extremely large increase in the magnitude of the feedback. Yet, an additional increase to $230^{\circ} \mathrm{C}$ apparently has little effect. A credible interpretation of these effects is one based on a temperature-sensitive system of clearances. With the inlet temperature low, i.e., about $30^{\circ} \mathrm{C}$, it is reasonable to assume that clearances between fuel rods, between fuel rods and hexes, and between hexes are at a minimum, since the core clamps and the expandable tightening rods were adjusted under these conditions. Except for mechanical imperfections in the rods, the core may be regarded as a tightly coupled system of individual rods. In principle, a rib-tocladding contact exists uniformly throughout the system. If the power is increased without changing the inlet temperature, the jackets will tend to expand radially; but since the temperature of the structure rings and the

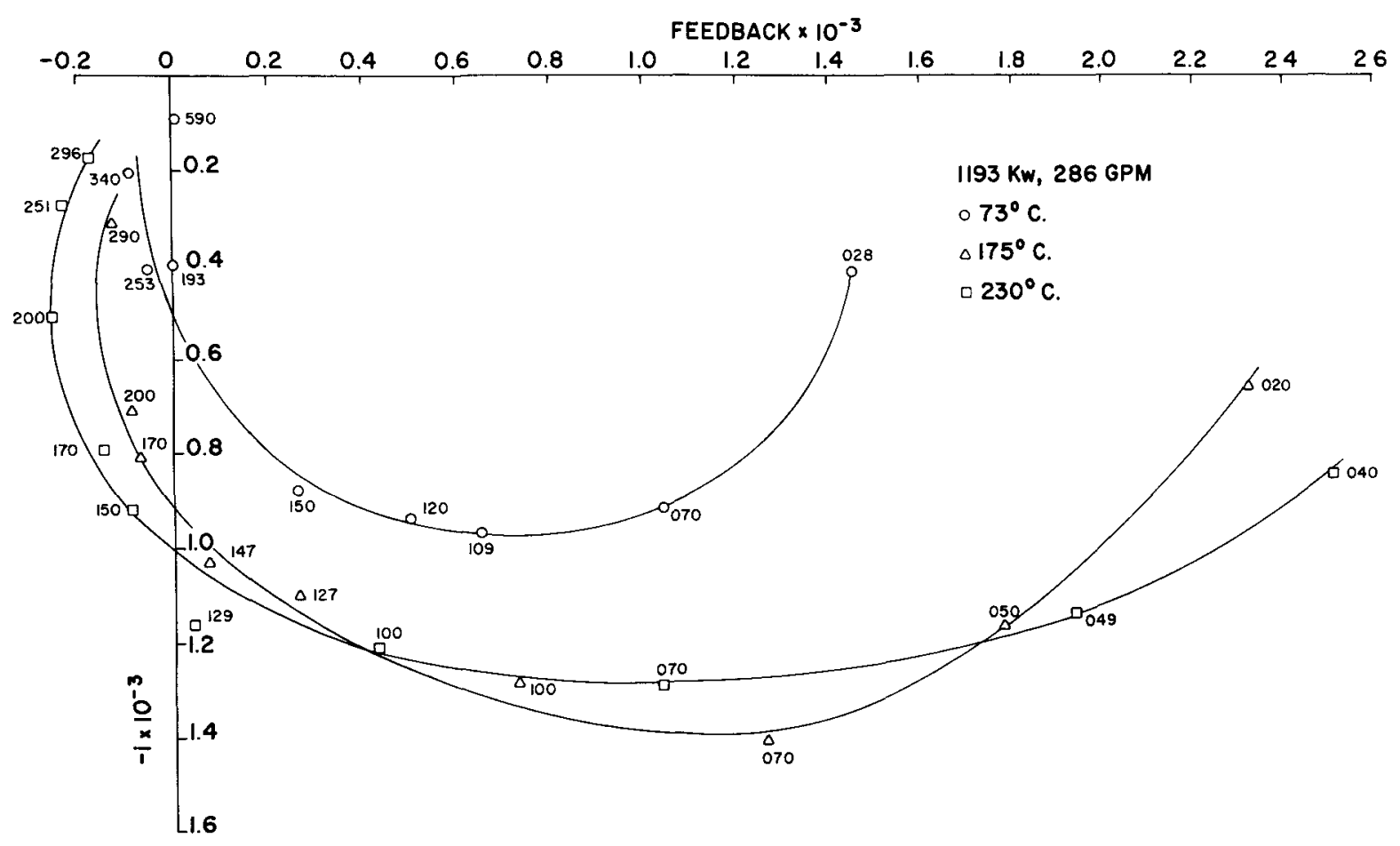

Fig. 17. Inlet Temperature Effect 
outer row of twelve blanket subassemblies remains at inlet temperature, the full radial component of jacket expansion will not be realized. Under these conditions, the power coefficient will reflect a decrease proportional to the constraining effect. In practice, small radial clearances most likely exist, even under idealized tightened conditions, and the radial component will certainly not be zero.

If the temperature of the inlet coolant is raised to $73^{\circ} \mathrm{C}$ to conform with the data of Fig. 17, all stainless steel components including the hexes and structure rings will expand by an amount dictated by the expansion coefficient of stainless steel $\left(18.4 \times 10^{-6} \Delta \mathrm{L} / \mathrm{L} /{ }^{\circ} \mathrm{C}\right)$. Jacket material will also expand, but since the expansion coefficient of Zircaloy-2 $\left(9.6 \times 10^{-6} \triangle \mathrm{L} / \mathrm{L} /{ }^{\circ} \mathrm{C}\right)$ is much smaller, the effect of an overall increase in temperature (at zero power) will be one which tends to open various clearance systems. In effect, the degree of radial coupling actually decreases as the temperature of the inlet coolant increases. Under these conditions more "room" is available to accept a colligative radial expansion, with the result that the radial power coefficient component is strong. If, however, the power is increased indefinitely, clearances will gradually close until the constraining influence of the outer hexes is again felt. At this point in power, the radial component of the power coefficient will decrease.

An additional increase in inlet temperature, say from 73 to $175^{\circ} \mathrm{C}$, will result in an additional increase in radial clearances. The results will be reflected by an increase in the power coefficient. From Fig. 17 it is clear that feedback data for $175^{\circ} \mathrm{C}$ are characterized by a power coefficient considerably larger than at $73^{\circ} \mathrm{C}$.

At some even higher inlet temperature, clearances between rods and between rods and hexes will be such that even at full power constraining effects will not be felt, i.e., enough room will exist to accept the full unconstrained effects of radial expansion. For these special conditions, the radial component of the power coefficient will reach its maximum. From Fig. 17 it seems likely that the "saturation" inlet temperature lies between 175 and $230^{\circ} \mathrm{C}$, since the increase between these values effects a relatively small, perhaps insignificant, increase in the magnitude of the feedback.

The effect of inlet temperature on feedback behavior introduces the interesting possibility that further increases in inlet temperature may lead to a decrease in the radial power coefficient component. If, for example, the clearances between fuel rods and between fuel rods and hexes increase to the extent that the core becomes completely uncoupled, the radial effects of jacket expansion may no longer be a colligative property. Under such, by no means incredible, conditions, the power coefficient may actually decrease to a value comparable in magnitude to that associated with the completely coupled and perfectly constrained core. 
H. Effect of Inlet Temperature on the Dynamic Power Coefficient

The effects of inlet temperature on feedback, discussed in the previous section, are also illustrated through a consideration of the dynamic power coefficient. By definition, the dynamic power coefficient is the extrapolated zero-frequency feedback reactivity divided by the power in kilowatts. It follows that the effects of inlet temperature on feedback should also be directly reflected in this parameter. Pertinent information is summarized in Table $\mathrm{X}$, which gives the dynamic power coefficient, $(\Delta \mathrm{k} / \mathrm{k} / \mathrm{kW})_{\mathrm{dy}}$, for the various data sets.

Table X

\section{SUMMARY OF DYNAMIC POWER COEFFICIENTS}

\begin{tabular}{|c|c|c|c|}
\hline $\begin{array}{c}\text { Power, } \\
k W\end{array}$ & $\begin{array}{l}\text { Inlet } \\
\text { Temp, } \\
{ }^{\circ} \mathrm{C}\end{array}$ & $\begin{array}{c}\mathrm{A}_{0}+\mathrm{B}_{0}(\mathrm{a}) \\
\times 10^{-3}, \Delta \mathrm{k} / \mathrm{k}\end{array}$ & $\begin{array}{l}\text { Dynamic Power Coeff, } \\
\quad(\triangle \mathrm{k} / \mathrm{k} / \mathrm{kW})_{\mathrm{dy}} \times 10^{-6}\end{array}$ \\
\hline 510 & 50 & 0.515 & 1.01 \\
\hline 878 & 51 & 1.05 & 1.20 \\
\hline 1193 & 73 & 1.65 & 1.38 \\
\hline 1120 & 173 & 2.30 & 2.05 \\
\hline 930 & 230 & 2.00 & 2.15 \\
\hline
\end{tabular}

In going from 510 to $878 \mathrm{~kW}$ (at essentially the same inlet temperature) the dynamic power coefficient increases from 1.01 to $1.20 \times 10^{-6} \Delta \mathrm{k} /$ $\mathrm{k} / \mathrm{kW}$. The increase in this instance is apparently the result of saturated slug bowing. Evidently, as discussed in Section IV-E, the power coefficient in the vicinity of $510 \mathrm{~kW}$ is characterized by a strong slug-bowing component which gradually weakens as saturation effects become more prevalent.

Increase of the power level from 878 to $1193 \mathrm{~kW}$ is manifested by an increase in the dynamic power coefficient from 1.20 to $1.38 \Delta \mathrm{k} / \mathrm{k} / \mathrm{kW}$. Unfortunately, the power increase was accompanied by an increase in the inlet temperature from 51 to $73^{\circ} \mathrm{C}$. Most likely the increase in the dynamic power coefficient is attributable to the temperature-sensitive clearance effects described above.

The effects of increasing the clearances between components is clearly indicated by the data sets listed in the sequence 73,173 , and $230^{\circ} \mathrm{C}$. Despite an actual decrease in power, an increase in inlet temperature from 73 to $173^{\circ} \mathrm{C}$ results in an increase from 1.38 to $2.05 \Delta \mathrm{k} / \mathrm{k} / \mathrm{kW}$. A further increase in inlet temperature from 173 to $230^{\circ} \mathrm{C}$, accompanied by a drop in 
power, increases the dynamic power coefficient from 2.05 to $2.15 \Delta \mathrm{k} / \mathrm{k} / \mathrm{kW}$. The fact that the dynamic power coefficient increases with temperature even though the power actually decreases, suggests that slug-bowing effects are essentially saturated at $930 \mathrm{~kW}$.

In principle, values of the dynamic power coefficient should agree with values established for the static power coefficient (see Section IV-F). An attempt to compare such values was unsuccessful for the following reasons. In the first place, the static power coefficient in the region of interest (full power) was not established with a sufficient degree of accuracy. In the second place, it is not obvious how slug hangup (upon saturation) affects the dynamic power coefficient.

It is clear, nevertheless, that changes in the inlet temperature effect strong changes in the feedback, and as all evidence indicates, the effect appears to be the consequence of a system of temperature-sensitive clearances.

\section{Stability Considerations}

From an inspection of the transfer function data, given in Figs. 4 through 8 , it is clear that the overall full-power kinetic behavior of the system is characterized by extreme stability. At low frequencies the phase and the amplitude of the feedback are such that the reactivity input is partially cancelled. At intermediate frequencies, 0.1 to $0.3 \mathrm{cycle} / \mathrm{sec}$, the input reactivity is subjected to a small but significant reinforcement. The immediate consequence is a small "bump" in the amplitude curve and a peaking of the associated phase at less negative values. Such behavior is the direct result of a feedback function which remains sufficiently large in the third (lower left-hand) quadrant to effect a partial cancellation of inverse zero-power gain vectors which of necessity lie in the first (upper right-hand) quadrant.

\section{Nyquist Stability Criterion}

Another measure of the stability may be obtained from the application of the Nyquist stability criterion. Since the transfer function $\mathrm{G}(\mathrm{i} \omega)$ is defined by

$$
G(i \omega)=\frac{G_{0}(i \omega)}{1+G_{0}(i \omega) H(i \omega)},
$$

the amplitude of the overall transfer function approaches infinity as the product $\mathrm{G}_{0}(i \omega) \mathrm{H}(\mathrm{i} \omega)$ approaches or exceeds - 1 . Under these special conditions, the system is unstable.

If it is assumed that feedback varies linearly with power, $\mathrm{G}_{0}(i \omega) \mathrm{H}(\mathrm{i} \omega)$ may be evaluated as a function of frequency for increasing 


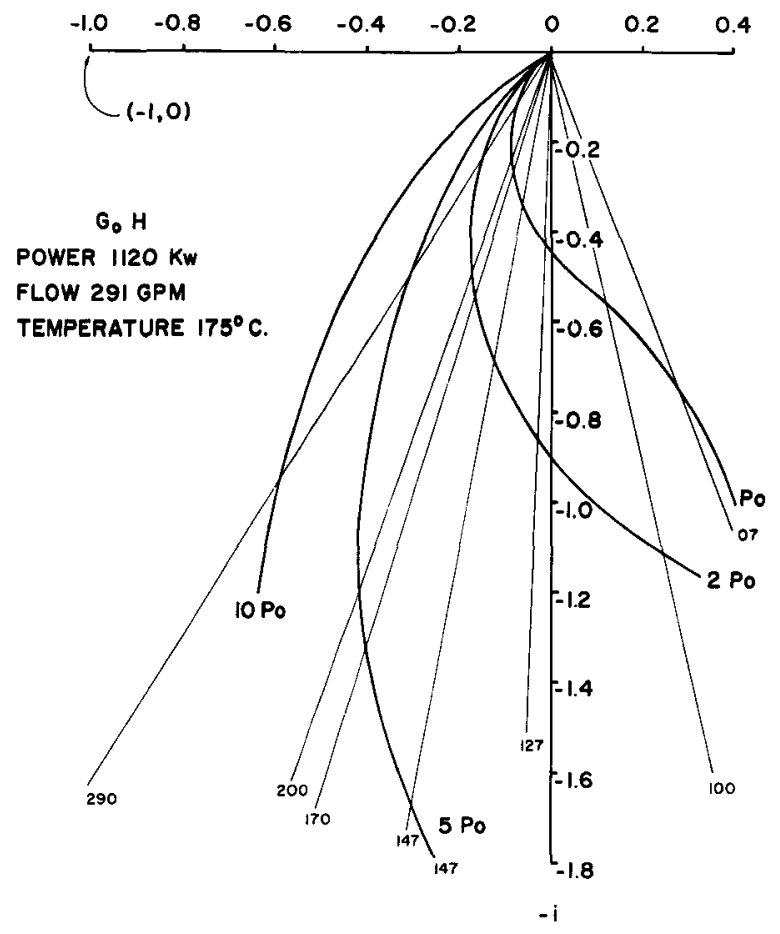

Fig. 18. Nyquist Stability Criterion levels of power. The result is a family of curves which approaches the $(-1,0)$ point as power is increased. An illustration of the principle is given in Fig. 18. The feedback is in all cases that established experimentally for $1120 \mathrm{~kW}, 29 \mathrm{gpm}$, and $175^{\circ} \mathrm{C}$. The intersection of the various $\mathrm{G}_{0}(i \omega) \mathrm{H}(i \omega)$ curves with the constant-frequency lines gives the value of $G_{0}(i \omega) H(i \omega)$ for a particular frequency at some specific multiple of $1120 \mathrm{~kW}$ (full power). From Fig. 18 it is obvious that the system is stable for all credible levels of power. A continuous increase in power beyond $10 \mathrm{P}_{0}$ (ten times nominal full power) could conceivably bring $G_{0}(i \omega) H(i \omega)$ into coincidence with the $(-1,0)$ point. The power level necessary to effect coincidence, however, would be an absurdity, considering limitations imposed by melting points and capabilities for heat removal. In a practical sense, the system could never be made unstable by a continuous power increase.

\section{Extrapolation of the Transfer Function}

Essentially the same information, but in transfer function form, is given in Fig. 19. The upper family of curves defines the amplitude for various multiples of full power. It is interesting to note that as the power increases, the resonance peak increases in magnitude, sharpens in definition, and moves in the direction of higher frequencies. Even at $10 \mathrm{P}_{0}$ the increased amplitude poses no operational problem.

The lower family of curves gives the phase of the transfer function as a function of frequencies for various multiples of power. The most significant features are a strong tendency for phase values to become more positive and a decided

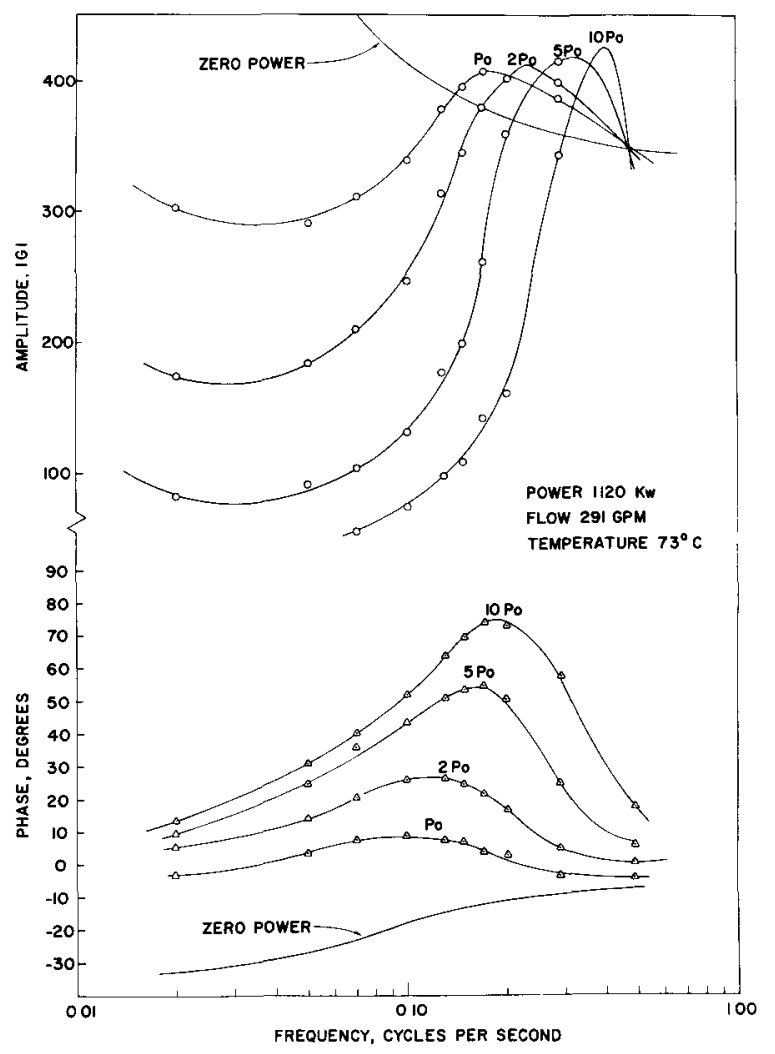

Fig. 19. Extrapolated Transfer Functions 
shift in the phase peak towards higher frequency. Although not illustrated, each of the other data sets, when extrapolated, gives essentially the same information.

\section{The Effect of $\beta_{\text {eff }}$ on Stability}

The effects of a low value of $\beta$ eff $(0.00304$ in contrast with 0.00685 for a similar $\mathrm{U}^{235}$ loading) on the kinetic behavior is illustrated in Figs. 20 and 21 . The first of these illustrates the case for a feedback

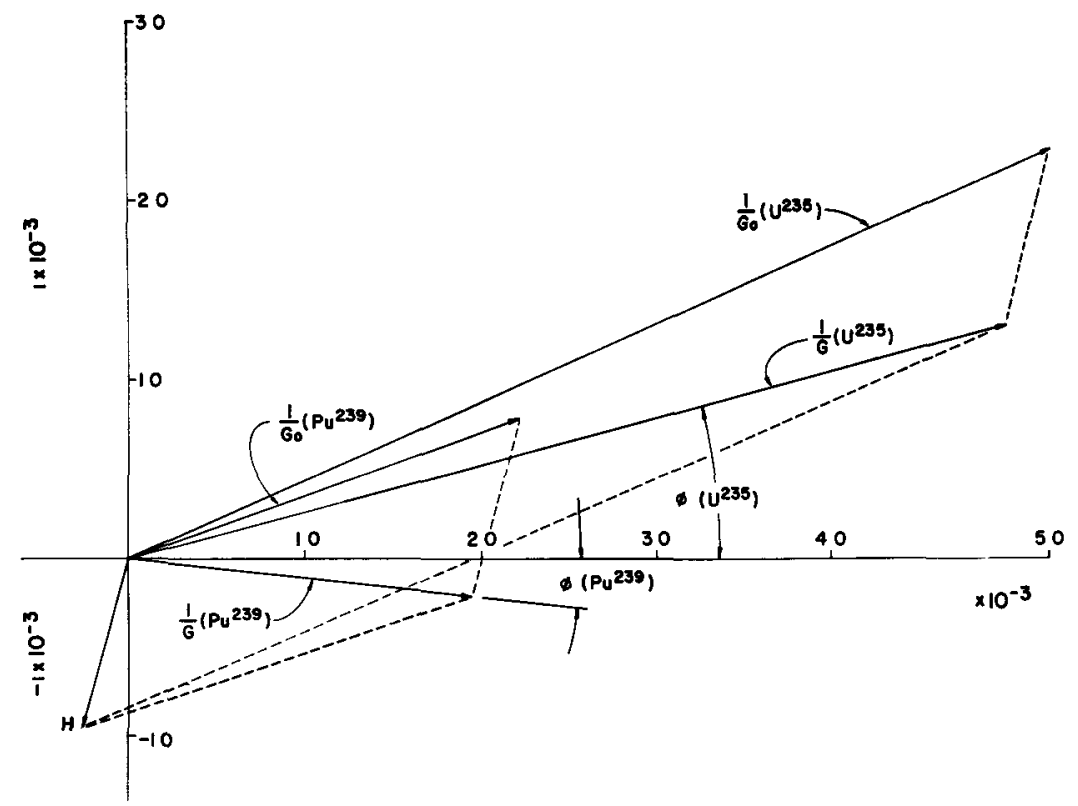

Fig. 20. The Effect of Third-quadrant Feedback on the Phase and Amplitude of the Transfer Function

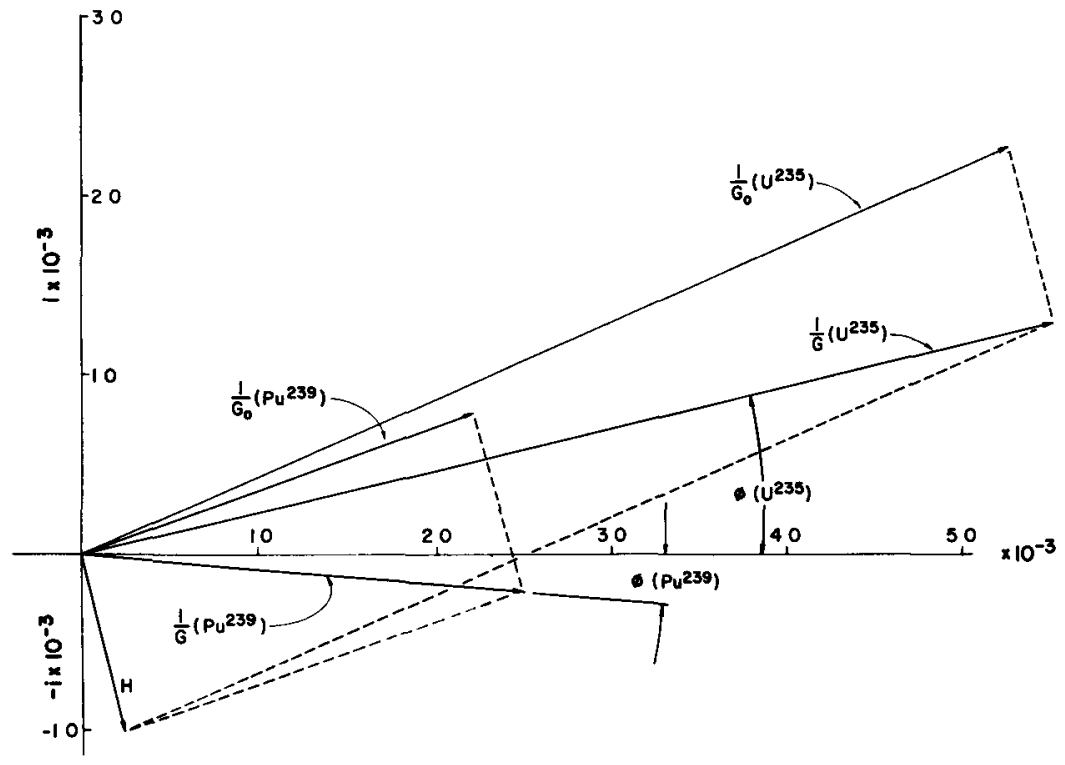

Fig. 21. The Effect of Fourth-quadrant Feedback on the Phase and Amplitude of the Transfer Function 
which interferes constructively with the reactivity input, i.e., the phasing is such that feedback reinforces the input. Shown in vector form are the feedback $H(i \omega)$ and the inverse zero-power gains associated with plutonium and uranium loadings. All three vectors have been evaluated at the same frequency. Since the inverse gain is simply

$$
1 / G(i \omega)=\left[1 / G_{0}(i \omega)\right]+H(i \omega)
$$

it follows that the fractional change in gain caused by a fixed feedback, i.e., common to both loadings, is significantly greater for the plutonium loading. In one sense, the $1 / G_{0}(i \omega)$ vector for $P_{u}{ }^{239}$ is more effectively cancelled by the feedback.

A graphic illustration of why phase leads were experienced in Mark IV and were missing in the Mark-III loading is also given in Fig. 20. Unless feedback vectors are unusually long, particularly at higher frequencies, it is difficult to shift the phase of $1 / G(i \omega)$ for a uranium loading into the fourth quadrant (where the phase angle becomes a lead). For a plutonium loading, on the other hand, a shift into the fourth quadrant is not only possible, but likely at full power and at intermediate frequencies. The consequence of shorter $1 / G_{0}(i \omega)$ vectors for plutonium is essentially this: for a feedback situation in which constructive interference is possible, a small value of $\beta$ eff tends to make the system less stable.

The converse situation, in which the feedback reactivity cancels a portion of the input, is illustrated in Fig. 21. In both cases, the $1 / G(i \omega)$ vectors are longer than those defining $1 / G_{0}(i \omega)$. From an inspection of the vector diagrams of Fig. 21 , it is clear that the fractional change in $1 / G(i \omega)\left(P u^{239}\right)$ exceeds that for $1 / G(i \omega)\left(U^{235}\right)$. In other words, a given feedback which cancels a portion of the input reactivity results in a proportionately greater reduction in the gain of a plutonium-fueled system. For the conditions illustrated in Fig. 21, i.e., for a feedback located in the fourth quadrant, the effect of a small value of $\beta_{\text {eff }}$ is one tending to make the system more stable. 


\section{SUMMARY, CONCLUSIONS, AND IMPLICATIONS}

The feedback function separated from transfer function measurements conducted with the plutonium loading in EBR-I can be described by a mathematical model characterized by two terms: one, prompt, small, and associated primarily with power changes in the fuel; and the other, relatively delayed, strong, and associated with expansion effects in the coolant, structure, and upper portion of the blanket. Substitution of experimental data into the mathematical model results in a set of time constants and power coefficients which adequately describes the feedback for a given set of operating conditions. In all cases, values for time constants are consistent with values established from heat transfer considerations. In general, the values established for the power coefficient of the delayed (primarily radial) term exceed by large factors the corresponding value established for the prompt fuel-expansion term.

Since the prompt term should outweigh the delayed term in importance, the empirical results are somewhat surprising. The anomaly has been attributed to slug-bowing effects which cancel all or nearly all of the usual prompt negative effects. For one particular set of operating conditions, the data indicate a net prompt positive power coefficient component. In this special instance, it seems likely the positive component from slug bowing was augmented by a limited amount of jacket bowing.

That slug bowing is an important mechanism is also indicated by the results of static measurements of power coefficient. All such data are consistent with a physical mechanism based on the bowing and saturation of individual slugs as the reactor power increases. For decreases from full power, saturated slugs tend to remain in position until the power drops below a saturation value. At this point, such slugs, and any above them, drop and effect a strong reactivity change. Such effects are statistical in nature and are apparently strongest in the power region $200-400 \mathrm{~kW}$.

Insofar as the stability and safety of the system are concerned, the effects of slug bowing are not particularly important. In all cases studied, the overall power coefficient was strongly negative and acted along a time base which, while delayed on a relative basis, was still sufficiently prompt to prevent strong reinforcement of input and feedback reactivities.

While the prompt power coefficient actually becomes positive for certain operating conditions, there is little reason for concern. The effect is small, $0.11 \times 10^{-6}$, in contrast with $2.8 \times 10^{-6} \Delta \mathrm{k} / \mathrm{k} / \mathrm{kW}$ estimated for Mark II, and exerts little or no influence on the routine operation of the system.

Although the system was not operated under reduced-flow conditions, it seems clear from the mathematical model that two effects would 
be felt if the system were operated at full power and reduced flow: the prompt term would become more positive (more slug and jacket bowing) and the delayed term would become more strongly delayed in time. The net result would be a strong tendency for both the phase and amplitude of the feedback to increase in the important third quadrant. Experimentally, such effects would be noted by a substantial increase in the amplitude of the transfer function and a decided shift in the associated phase toward higher leads. It is unfortunate that reduced-flow experiments could not be carried out, but in view of strict limitations imposed on maximum fuel temperatures, this was not possible.

Accepting the unrealistic assumption of power coefficient linearity over a wide range of power, the application of the Nyquist stability criterion to full-flow, full-power data leads to the conclusion that the system could never be forced to instability through continuous power increases at full flow. Since the instability point lies well above 10 times nominal full power, the limitations of melting points and heat removal become of more immediate significance. For reduced-flow operation, the hypothetical instability power would be much lower. Crude estimates, based on fullflow data, however, indicate that the instability power would still lie considerably above nominal design specifications.

A strong dependence of feedback on the temperature of the inlet coolant was noted, with the sense of the dependence such that increases in the inlet temperature increased the magnitude of the feedback. The effect may be explained in terms of temperature-sensitive systems of clearances which exist between fuel rods, between fuel rods and hexes, and between hexes. At low inlet temperatures, the fuel rods are rigidly coupled and clearances are small. With the outer ring of hexes and structure rings maintained at inlet coolant temperature, power increases are manifested by radial jacket expansion which tends to close remaining clearances. Under these conditions, jacket expansion is constrained by the outer ring of hexes and the full radial power coefficient is not realized.

Increases in the inlet temperature lead to a preferential expansion of the constraining members with a resulting increase in all clearance systems. (The linear expansion coefficient of stainless steel is approximately twice that for Zircaloy-2). With an increase in clearances, more "room" is available in the hexes for radial expansion and the power coefficient increases. It is interesting to note that the only case in which a prompt positive power coefficient was detected was one characterized by the highest inlet temperature reached, i.e., $230^{\circ} \mathrm{C}$. Although not definitive, the evidence suggests that clearances were sufficiently opened to permit a limited amount of jacket bowing which, in turn, reinforced the slug-bowing effect. 
A study of the feedback data as a function of inlet temperature results in the conclusion that additional increases in inlet temperature beyond some unspecified value, effect little or no increase in the magnitude of the reactivity effect. Apparently, at some particular temperature clearances have been opened to the extent that the entire radial expansion of the jackets can be accommodated without constraint. The effects of additional increases in inlet temperature on feedback are manifested by an increase in the rod-bowing component, which apparently cancels any additional increase in the negative radial-expansion effect.

The effects of operating a system fueled with plutonium are manifested primarily as an increased sensitivity towards reactivity perturbations. For a feedback which reinforces the input, the neutron kinetics are such that the system tends to be less stable (relative to the case for $\mathrm{U}^{235}$ fuel). On the other hand, for a feedback which cancels a portion of the input, the system will tend to be more stable. As a consequence, if slugbowing and rod-bowing effects could be eliminated, it seems likely the kinetic behavior of a plutonium-fueled system would be more stable than that of its $\mathrm{U}^{235}$-fueled counterpart.

The fact that slug-bowing effects can effect an important reduction in the prompt negative fuel coefficient has several interesting and perhaps important implications. As the trend toward larger, more dilute cores continues, an increasing emphasis will be placed on prompt negative power coefficient components which act to reduce reactivity in the event of an inadvertent prompt critical insertion. If, however, slug-bowing and jacketbowing effects are sufficiently large, they may greatly reduce or even override prompt negative effects associated with Doppler broadening and axial fuel expansion. For these special, but not improbable, conditions, the system would be left with little or no inherent shutdown capability.

Another important implication concerns specific experiments aimed at an evaluation of the Doppler effect in dilute FARET loadings. (13) In one of these, it is planned to increase power and flow in such a manner that coolant, cladding, and structural temperatures remain unchanged. The change in control rod position may then be used as a measure of the reactivity lost as the result of the power increase. The assumption has been that the reactivity loss would be the result of Doppler broadening and axial fuel expansion. The Doppler effect would then be separated by a simple subtraction of a calculated value for fuel expansion from the measured reactivity effect. The effects of a failure to consider slug bowing would be reflected by an error in the value established for the Doppler coefficient. Clearly, additional thinking is necessary.

Since the fuel in EBR-II also consists of sodium-bonded slugs, it is possible that bowing may also effect the kinetic response of this system to 
a measurable degree. Although it is highly unlikely that such effects will introduce operational problems, it is reassuring, in some respects, to be aware of this interesting possibility.

As a final implication, the fact that power coefficients in small, high-power-density systems depend strongly on clearances, bowing effects, and differential structural expansion should be of interest to the designers of space-oriented systems. Failure to anticipate strong nonlinearities in the power coefficient and reversals of sign could result in poorly designed and perhaps inadequate systems of control.

\section{ACKNOW LEDGMENTS}

The authors gratefully acknowledge the assistance of $\mathrm{Mr}$. C. B. Doe, who was primarily responsible for the operation and maintenance of the null balance equipment, and other members of the EBR-I operating staff. The advice and assistance of Messieurs D. Mohr, R. N. Curran, and R. D. DeForest are also gratefully acknowledged.

\section{REFERENCES}

1. Jurney, E. T., The Los Alamos Fast Reactor, Nuclear Eng., Part III, Series 50, No. 13,191 (1954).

2. Swickard, E. O., Los Alamos Molten Plutonium Experiment (LAMPRE) Hazards Report, LA-2327 (Dec 1959).

3. DeBoisBlanc, D., and Marsden, R. S., Operation of the MTR on a Plutonium Loading, IDO-16508 (Dec 1958).

4. Smith, R. R. et a1., The Breeding Ratio of a Plutonium Loading in EBR-I, ANL-6789 (Feb 1964).

5. McCarthy, W. J. et al., Studies of Nuclear Accidents in Fast Power Reactors, Proceedings of the Second United Nations International Conference on the Peaceful Uses of Atomic Energy, Geneva, Switzerland, 12, 207 (1958).

6. Okrent, D., A Review of the Nuclear Aspects of Fast Reactor Safety, I.A.E.A. Seminar on the Physics of Fast and Intermediate Reactors, Vienna, Austria, August (1961).

7. Lichtenberger, H. V. et al., Operating Experience and Experimental Results Obtained from a NaK Cooled Fast Reactor, Proceedings of the First United Nations International Conference on the Peaceful Uses of Atomic Energy, Geneva, Switzerland, 3, 345 (1956).

8. Kinchin, G. H., The Stability of Fast Reactors, RP/M83, AERE, Harwell (June 1956). 
9. Bethe, H. A., Reactor Safety and Oscillator Tests, APDA-I17 (Oct 1956).

10. Thalgott, F. W. et al., Stability Studies on EBR-I, Proceedings of the Second International Conference on the Peaceful U ses of Atomic Energy, Geneva, Switzerland, 12, 242 (1958).

11. Smith, R. R. et al., Instability Studies with EBR-I, Mark III, ANL-6266 (Dec 1960).

12. Smith, R. R. et al., An Analysis of the Stability of EBR-I, Marks I-III, and Conclusions Pertinent to the Design of Fast Reactors, I.A.E.A. Seminar on the Physics of Fast and Intermediate Reactors, Vienna, Austria, August, 1961.

13. Smaardyk, A., Fast Reactor Test Facility, Experimental Program, Interim Report, Argonne National Laboratory (April 1963).

14. Haroldsen, R. O. et al., Hazards Summary Report, EBR-I, Mark IV, ANL-6411 (Sept 1961).

15. Boland, J. F. et al., A Measurement of the Transfer Function of a Fast Critical Facility, ANL-5782 (Sept 1957).

16. Schultz, M. A., Control of Nuclear Reactors and Power Plants, McGrawHill Book Co., Inc., New York (1955).

17. Loewenstein, W., Argonne National Laboratory, unpublished work (Jan 1964).

18. Templin, L. J., Reactor Physics Constants, ANL-5800, July 1963.

19. McKell, Lynn, private communication (Jan 1964).

20. Wakabayaski, Jiro, Analytical Study of the Transfer Function of EBR-I, Mark IV, ANL-6773 (Sept 1963).

21. Mohr, Dale, Argonne National Laboratory, unpublished work (1964).

22. Donohue, H. F., and Keaton, R. W., Fuel Rod-Bowing in SRE, NAASR-6878 (June 1962).

23. Storrer, F., Temperature Response of Power, Inlet Coolant Temperature, and Flow Transients in Solid Fuel Reactors, APDA-132 (June 1959).

24. Mohr, Dale, private communication, Jan 1964.

25. Bode, H. W., Network Analysis and Feedback Amplifier Design, John Wiley and Sons, New York (1945). 